\title{
Restoration of proximal tubule flow- activated transport prevents cyst growth in polycystic kidney disease
}

\author{
Zhaopeng Du, ${ }^{1}$ Xin Tian, ${ }^{2}$ Ming Ma, ${ }^{2}$ Stefan Somlo, ${ }^{2}$ Alan M. Weinstein, ${ }^{3}$ and Tong Wang ${ }^{1}$ \\ 'Department of C\&M Physiology and 'Department of Internal Medicine (Nephrology), Yale University, New Haven, \\ Connecticut, USA. ${ }^{3}$ Department of Physiology and Biophysics, Weill Medical College of Cornell University, New York, \\ New York, USA.
}

\begin{abstract}
Flow-activated $\mathrm{Na}^{+}$and $\mathrm{HCO}_{3}{ }^{-}$transport in kidney proximal tubules (PT) underlies relatively constant fractional reabsorption during changes in glomerular filtration rate (GFR) or glomerulotubular balance (GTB). In view of hypothesized connections of epithelial cilia to flow sensing, we examined flow-activated transport in 3 polycystic kidney disease-related mouse models based on inducible conditional KO of Pkd1, Pkd2, and Kif3a. PTs were harvested from mice after gene inactivation but prior to cyst formation, and flow-mediated PT transport was measured. We confirm that higher flow increased both $\mathrm{Na}^{+}$and $\mathrm{HCO}_{3}{ }^{-}$absorption in control mice, and we observed that this flow effect was preserved in PTs of $\mathrm{Pkd1}^{-/-}$and $\mathrm{Kif3a}^{-/-}$mice. However, flow activation was absent in $\mathrm{Pkd2}^{+/-}$and $\mathrm{Pkd2}^{-/-} \mathrm{PT}$. In heterozygous ( $\mathrm{Pkd2}^{+/-}$) mice, a dopamine receptor 1 (DA1) antagonist (SCH23390) restored transport flow sensitivity. When given chronically, this same antagonist reduced renal cyst formation in $\mathrm{Pkd2}^{-/-}$, as evidenced by reduced kidney weight, BUN, and the cystic index, when compared with untreated mice. In contrast, SCH23390 did not prevent cyst formation in $\mathrm{Pkd1}^{-/-}$mice. These results indicate that $P$ kd2 is necessary for normal GTB and that restoration of flow-activated transport by DA1 antagonist can slow renal cyst formation in Pkd2 $^{-1-}$ mice.
\end{abstract}

Authorship note: $\mathrm{ZD}$ and $\mathrm{XT}$ are cofirst authors and contributed equally to this work.

Conflict of interest: The authors declare that no conflict of interest exists.

Copyright: (c) 2021, Du et al. This is an open access article published under the terms of the Creative Commons Attribution 4.0 International License.

Submitted: November 20, 2020

Accepted: April 21, 2021

Published: April 22, 2021

Reference information: /CI Insight. 2021;6(10):e146041.

https://doi.org/10.1172/jci.

insight.146041.

\section{Introduction}

In proximal tubules (PT), flow-modulated salt and water reabsorption is largely responsible for glomerulotubular balance (GTB), namely the constancy of fractional distal $\mathrm{Na}^{+}$delivery during variations in glomerular filtration rate (GFR) $(1,2)$. Isolated perfused mouse PT have been fruitful for examining the flow dependence of $\mathrm{Na}^{+}$and $\mathrm{HCO}_{3}^{-}$transport in vitro. It has been demonstrated that fluid shear stress (FSS) at the luminal surface of the PT cell modulates activity of the $\mathrm{Na}^{+} / \mathrm{H}^{+}$exchanger (NHE3) and the $\mathrm{H}^{+}$-ATPase (3). Available evidence implicates brush border microvilli as the afferent FSS sensors, and analytical predictions of brush border FSS fit experimental observations (4). Signal transduction was actin dependent, since disruption by cytochalasin eliminated flow-dependent changes in transport (5). Flow-stimulated $\mathrm{Na}$ absorption was abolished completely by inhibition of NHE3, and it was also abolished in NHE3-KO mice. Flow-stimulated $\mathrm{HCO}_{3}^{-}$absorption was substantially reduced by NHE3 inhibition, and it was completely abolished by inhibiting both NHE3 and H-ATPase (3). Specifically, luminal membrane FSS stimulates NHE3 trafficking to the apical membrane by a mechanism that requires an intact actin cytoskeleton, while $\mathrm{H}^{+}$-ATPase trafficking depends on the microtubules (6). Cell volume integrity is preserved during flow-dependent transport, since luminal FSS also modulates $\mathrm{Na}^{+} / \mathrm{K}^{+}$-ATPase translocation to the peritubular membrane (6). An important parameter of FSS-dependent $\mathrm{Na}^{+}$reabsorption is the flow sensitivity, defined as the fractional change in transport relative to the fractional change in FSS. With respect to the important regulators of $\mathrm{PT}$ transport, angiotensin acts to increase absolute $\mathrm{PT} \mathrm{Na} \mathrm{Na}^{+}$and $\mathrm{HCO}_{3}^{-}$reabsorption with little perturbation of their flow sensitivity (7). Conversely, dopamine does little to perturb baseline fluxes but markedly blunts flow sensitivity. In these experiments, the dopamine receptor 1 (DA1) antagonist SCH23390 increased flow sensitivity of $\mathrm{Na}^{+}$and $\mathrm{HCO}_{3}{ }^{-}$reabsorption to supernormal values (8).

$P k d 1$ and $P k d 2$ are both localized in primary cilia and also in other cellular locations $(9,10)$. Polycystin-1 (PC1), the $P k d 1$ gene product, is a 4302-amino acid protein consisting of a large, 3000 -amino acid 
extracellular domain; 11 transmembrane domains; and an intracellular carboxyl terminus. It may function as a mechanosensor or chemosensor (10). Polycystin-2 (PC2), the Pkd2 gene product, is a nonselective calcium permeable cation channel belonging to the TRP channel family. The cellular locations of PC2 have been reported at the cilia and ER, and they can function as $\mathrm{Ca}^{2+}$ channels in both locations (11-15). Patch clump recordings identify PC2 as an essential ion channel subunit in the primary cilia of the renal collecting duct epithelium (15). The functional role of the primary cilia has been studied by using cultured MDCK cell and in perfused collecting tubules. It was demonstrated that calcium signals are the major second messenger mechanisms for primary cilium-mediated mechanosensation in MDCK cells and in cortical collecting ducts $(4,16)$. It was also demonstrated that high flow rate increased intracellular $\mathrm{Ca}^{2+}$ concentration and is attenuated in the collecting duct of monocilium-impaired orpk mice (17). Kinesin-like protein (Kif3a), also known as microtubule plus end-directed kinesin motor 3A, is responsible for plus end-directed microtubule sliding activity and is essential for cilia formation. The tissue-specific inactivation of Kif3a in renal tubular epithelial cells results in viable offspring with normal-appearing kidneys at birth, but renal cysts begin to develop in the kidney at P5 and cause renal failure by P21 (18). We have used Kif3aKO mice, which were generated by flox/flox crossed with pax8-rtTA and Tet-O-Cre mice. Pax8-rTA is a whole nephron Cre (19), and the Tet-O is a Cre with tetracycline responsive element (20).

Previously, we have investigated the impact of calcium signals in the regulation of GTB and have shown that IP3 receptor-mediated intracellular $\mathrm{Ca}^{2+}$ signals were critical for transduction of microvillus torque to increase $\mathrm{Na}^{+}$and $\mathrm{HCO}_{3}^{-}$absorption (21). It has been reported that primary cilia has a mechanosensiry function in collecting ducts, mediated by increases in intraculluar $\mathrm{Ca}^{2+}(4,16,17)$. However, whether PC1, PC2, or primary cilia have mechanosensory roles in flow modulation of PT transport has not been examined. Availability of the kidney-selective $\mathrm{KO}$ of $P k d 1, P k d 2$, and $K i f 3 a$ in animals provides unique tools for investigating whether these molecules are important for mechanosensation in flow-mediated PT transport. We investigated the flow-dependent PT transport in 3 major polycystic kidney disease (PKD) and ciliopathy animal models of $P k d 1$-, Pkd2-, and Kif3a-KO mice after gene KO but prior to cyst formation. We found that flow dependence of PT reabsorption was absent in $P k d 2^{+/-}$and $P k d 2^{f / f f}$;Pax8-rtTA;Tet-O-Cre precystic mice but was preserved in both

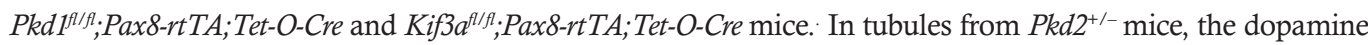
antagonist SCH23390 restored transport sensitivity to flow. When SCH23390 was administered chronically,

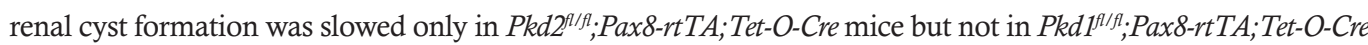
mice. When examined in a mathematical model of the full kidney, abrogation of PT flow-dependent transport produced wider swings in intratubular pressure in conjunction with GFR variations. Our experimental data show that applications of a DA1 antagonist at the precystic stage prevented renal cyst formation only in $P k d 2^{-/-}$, which had impaired GTB, but not in $P k d 1^{-/-}$, which had intact GTB. These are the results that would be expected if swings in intratubular pressure played a pathophysiological role in cyst formation of $P k d 2$.

\section{Results}

Flow-stimulated $\mathrm{Na}^{+}$and $\mathrm{HCO}_{3}^{-}$absorption in $\mathrm{Pkd}^{+/-}$and $\mathrm{Pkd}^{-/-}$mice PT. Age-matched (8-week-old) male and female mice were used for microperfusion experiments. $P k d 2^{+/-}$and its WT control were generated as

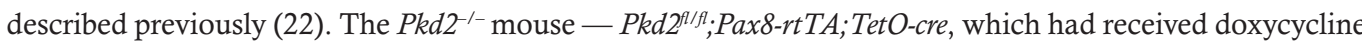
induction from P28-P42 - and its control is $P k d 2^{f / f l}$ (20) were used for the study. We observed no morphological changes of the kidneys from the Pkd1-, Pkd2-, and the Kif3a-KO mice 2 weeks after the induction (at the age of 8 weeks) and observed some dilated kidney tubules after 5 weeks of induction; renal cysts developed from 8 weeks of induction in $P k d 1$ and $P k d 2 \mathrm{KO}$ mice (20). The precystic mice were 8 weeks old ( 2 weeks after the induction) and were used for the microperfusion experiments.

Table 1 describes the geometry of tubules from all studies, perfused at either low or high flow rates. The inner diameter (ID) and outer diameter (OD) of the perfused tubule under low and high flow rates were measured. Subtraction of the cross-sections defined by OD and ID provides an estimate of cell volumes in all studies $(5,8)$. As shown in Table 1 , higher flow rate significantly increased both ID and OD in all groups of mice. The ID was increased from $50 \%$ to $70 \%$, and the OD was increased from $5 \%$ to $7 \%$ in the transitions from low to high flow rates. Presumably, increases in ID and OD with higher perfusion rates reflect increases in luminal hydrostatic pressure so that these diameter increases reflect tubule compliance. Comparison among the groups revealed no compliance differences between controls and the various $\mathrm{KO}$ and $P k d 2^{+/-}$groups. In contrast, the cell volumes under low and high flow rates were not significantly different in all groups of mice (Table 1). These results are in agreement with our previous studies that axial flow 
alters ion transporters on both apical and basolateral membranes and kept cell volumes relatively constant $(6,23)$. The last column of the table, $\mathrm{T} / \mathrm{T}_{\mathrm{r}}$, is an estimate of the change in luminal drag in going from low to high flow, specifically the relative torque on the brush border microvilli when viewed as levers $(3,5)$. This drag is approximately proportional to the luminal fluid velocity and, thus, varies directly with flow rate and inversely with the luminal cross-sectional area.

Figure 1, Table 2, Table 3, and Table 4 summarize results of flow-stimulated $\mathrm{Na}^{+}$and $\mathrm{HCO}_{3}^{-}$absorption in control, $P k d 2^{+/-}$, and $P k d 2-\mathrm{KO}\left(P k d 2^{f / f l} ;\right.$ Pax8-rtTA; Tet-O-Cre $)$ PT. Figure $1 \mathrm{~A}$ shows the net $\mathrm{Na}^{+}\left(\mathrm{J}_{\mathrm{Na}}\right)$, and Figure $1 \mathrm{C}$ shows the net $\mathrm{HCO}_{3}^{-}\left(\mathrm{J}_{\mathrm{HCO}}\right)$ absorption in control $(P k d 2 \mathrm{WT})$ and $P k d 2^{+/-}$mouse PT under low and high flow rates. Similar to results reported previously, $\mathrm{J}_{\mathrm{Na}}$ increased $47.4 \%$ and $\mathrm{J}_{\mathrm{HCO} 3}$ increased $96 \%$ in the control group when the flow rate increased from $5.7 \mathrm{~nL} / \mathrm{min}$ to $24 \mathrm{~nL} / \mathrm{min}$ (3). The $\mathrm{J}_{\mathrm{Na}}$ increased from 134.2 to $197.8 \mathrm{pmol} / \mathrm{min} / \mathrm{mm}(P<0.001)$, and the $\mathrm{J}_{\mathrm{HCO} 3}$ increased from 70.8 to $139 \mathrm{pmol} / \mathrm{min} / \mathrm{mm}$ $(P<0.001)$ in WT control. In $P k d 2^{+/-}$mice, the flow effect on $\mathrm{J}_{\mathrm{Na}}$ was completely abolished, and on $\mathrm{J}_{\mathrm{HCO}_{3}}$ it was considerably reduced (increase of $28 \%$ ). Figure $1 \mathrm{~B}$ shows the net $\mathrm{Na}\left(\mathrm{J}_{\mathrm{Na}}\right)$ and Figure $1 \mathrm{D}$ shows the

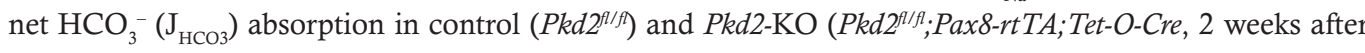
the induction). In addition to the slight reduction of $\mathrm{J}_{\mathrm{Na}}$ at the low flow rate $(77.3$ versus $137.8 \mathrm{pmole} / \mathrm{min} /$ $\mathrm{mm} ; P<0.05)$ and $\mathrm{J}_{\mathrm{HCO} 3}(58.1$ versus $74 \mathrm{pmole} / \mathrm{min} / \mathrm{mm} ; P>0.05)$, the flow effect is also completely gone in the $P k d 2-\mathrm{KO}$ mice compared with the control.

Flow-stimulated $\mathrm{Na}^{+}$and $\mathrm{HCO}_{3}^{-}$absorption in Pkd1- and Kif3a-KO mice PT. Figure 2 summarizes results

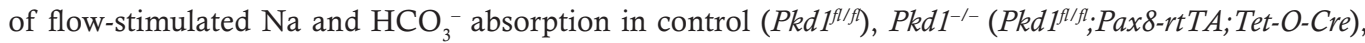
and $\mathrm{Kif3a}^{-/-}\left(\mathrm{Kif3a}^{f l / f} ; \mathrm{Pax} 8-\mathrm{rtTA}\right.$; Tet-O-Cre $)$ mouse PT. KIf3a is a subunit of kinesin-II, which is essential for primary cilia formation. We studied PT functions in $\mathrm{Kif3}^{A l / f} ; \mathrm{Pax} 8$-rtTA;Tet-O-Cre mice at the precystic stage (8-week-old mice, 2 weeks after the induction). Mice at this stage showed absence of primary cilia in the PT, but cysts were not yet formed (20). Figure 2, A and $\mathrm{C}$, shows $\mathrm{Na}^{+}$and $\mathrm{HCO}_{3}^{-}$absorption in control $\left(P k d 1^{f / f f}\right)$ and in $P k d 1^{-/-}$mouse PT under low and high flow rates. Increasing flow from 5 to $20 \mathrm{~nL} /$ min significantly increased the $\mathrm{J}_{\mathrm{Na}}$ and $\mathrm{J}_{\mathrm{HCO} 3}$ in control tubules, as we reported previously (3). In $P k d 1^{-/-}$, the flow effects are well preserved, and increasing flow rate produced similar stimulation of both $\mathrm{J}_{\mathrm{Na}}$ and $\mathrm{J}_{\mathrm{HCO} 3}$ in the $P k d 1^{-1-}$ compared with the control mice. When flow rate increased, $\mathrm{J}_{\mathrm{Na}}$ increased by $51 \%$ and $53 \%$ and $\mathrm{J}_{\mathrm{HCO} 3}$ increased by $81 \%$ and $99 \%$ in control and $P k d 1^{-/-}$, respectively $(P>0.05)$. As shown in Figure 2, B and D, flow effects were also well preserved in $\mathrm{Kif3}^{-/-}$mice, since similar increments were produced in both $\mathrm{J}_{\mathrm{Na}}$ and $\mathrm{J}_{\mathrm{HCO} 3}$ by higher flow rates in $\mathrm{Kif3}^{-/-}$compared with the control. When flow rate increased, $\mathrm{J}_{\mathrm{Na}}$ increased by $48 \%$ and $45 \%$ and $\mathrm{J}_{\mathrm{HCO} 3}$ increased by $84 \%$ and $99 \%$ in control and $\mathrm{Kifl}^{-/-}$, respectively $(P>0.05)$. These results indicate that neither $P k d 1$ nor primary cilia are necessary for flow stimulation of $\mathrm{Na}^{+}$and $\mathrm{HCO}_{3}^{-}$absorption in PT.

Effect of dopamine receptor antagonist on flow-stimulated $\mathrm{Na}^{+}$and $\mathrm{HCO}_{3}^{-}$absorption. Dopamine-stimulated NHE3 endocytosis reduces microvillous expression of NHE3 (24) and blocks the norepinephrine-stimulated $\mathrm{Na}^{+}$transport in PT (25). Previously, we have demonstrated that dopamine inhibits flow-stimulated NHE3 activity by activation of the DA1 receptor (8). Blocking the DA1 receptor by SCH23390 not only restored flow-stimulated transport, but also increased the tubule sensitivity to flow (8). Here, we examined the effect of SCH23390 $\left(1 \times 10^{-5} \mathrm{M}\right)$ on flow-stimulated $\mathrm{Na}^{+}$and $\mathrm{HCO}_{3}^{-}$absorption in $\mathrm{Pkd}^{+/-}$mice, in which flow-dependent transport is impaired. As shown in Figure 3, flow-stimulated $\mathrm{Na}^{+}$absorption was completely gone (Figure $3 \mathrm{~A}$ ) and $\mathrm{HCO}_{3}^{-}$was substantially reduced (Figure 3D) in $P k d 2^{+/-}$mice. DA1 inhibition restored the flow effect on $\mathrm{Na}^{+}$and partially restored the flow effect on $\mathrm{HCO}_{3}^{-}$in $P k d 2^{+/-}$mice. Figure $3, \mathrm{~B}$ and $\mathrm{D}$, shows the fractional changes of $\mathrm{J}_{\mathrm{Na}}$ and $\mathrm{J}_{\mathrm{HCO} 3}$ calculated from the flow rates at 5 to $20 \mathrm{~nL} / \mathrm{min}$. The fractional changes in $\mathrm{J}_{\mathrm{Na}}$ were $47.4 \%,-9.3 \%$, and $56.8 \%$; the fractional changes in $\mathrm{J}_{\mathrm{HCO} 3}$ were $96 \%$, $28.2 \%$, and $58.6 \%$ in WT control, $\mathrm{Pkd}^{+/-}$, and $\mathrm{Pkd2} 2^{+/-}+\mathrm{SCH} 23390$, respectively. SCH23390 increased tubule response to flow stimulation on both $\mathrm{Na}^{+}$and $\mathrm{HCO}_{3}{ }^{-}$absorption in $\mathrm{Pkd2}{ }^{+/-}$mice. $\mathrm{SCH} 23390$ had no effect on flow-stimulated tubule transport in WT mice. As shown in Figure 3, E and F, the increments in both $\mathrm{J}_{\mathrm{Na}}$ and $\mathrm{J}_{\mathrm{HCO} 3}$ in the absence or presence of SCH23390 were similar in control tubules.

Effect of dopamine receptor antagonist on renal cyst formation in Pkd2-KO mice. To study whether a DA1 receptor antagonist can prevent renal cyst formation, the DA1 antagonist SCH23390 was administered in 8-week-old mice through the drinking water $\left(0.1 \mathrm{mg} / \mathrm{kgBW} /\right.$ day) for 6 weeks in control $\left(P k d 2^{f / f f}\right)$ and $P k d 2^{-/-}\left(P k d 2^{f l f f} ;\right.$ Pax8-rtTA;Tet-O-Cre $)$ mice 2 weeks after induction, with doxycycline from $\mathrm{p} 28$ to $\mathrm{p} 42$. After 6 weeks of treatment, the animals were allowed a 4-week extension for further cystic growth; they were then euthanized at the age of 18 weeks for cyst analysis. The kidney weight/body weight ratio, BUN, and 
Table 1. Flow-induced changes of tubule diameter, cell volume and torque in mouse PT

\begin{tabular}{|c|c|c|c|c|c|c|c|}
\hline Groups & $N / N$ & $\begin{array}{c}\text { Vo } \\
\text { (nL/min) }\end{array}$ & $\underset{(m m)}{L}$ & Volume $\left(\mu \mathrm{m}^{3}\right)$ & $\begin{array}{c}\text { ID } \\
(\mu \mathrm{m})\end{array}$ & $\begin{array}{l}\text { OD } \\
(\mu \mathrm{m})\end{array}$ & $\mathrm{T} / \mathrm{Tr}$ \\
\hline Pkd2 WT & $\begin{array}{l}13 / 7 \\
13 / 7\end{array}$ & $\begin{array}{l}5.7 \pm 0.50 \\
24.0 \pm 1.10\end{array}$ & $\begin{array}{l}1.1 \pm 0.07 \\
1.1 \pm 0.07\end{array}$ & $\begin{array}{c}917.2 \pm 18.7 \\
874.5 \pm 12.6 \mathrm{~ns}\end{array}$ & $\begin{array}{l}10.3 \pm 0.21 \\
17.1 \pm 0.17^{A}\end{array}$ & $\begin{array}{l}35.7 \pm 0.36 \\
37.5 \pm 0.20^{A}\end{array}$ & $\begin{array}{c}1.00 \pm 0.07 \\
1.28 \pm 0.04^{A}\end{array}$ \\
\hline $\mathrm{Pkd2}^{+/-}$ & $\begin{array}{l}11 / 7 \\
11 / 7\end{array}$ & $\begin{array}{l}6.7 \pm 0.85 \\
22.3 \pm 0.77\end{array}$ & $\begin{array}{l}0.88 \pm 0.02 \\
0.88 \pm 0.02\end{array}$ & $\begin{array}{c}906.8 \pm 14.6 \text { NS } \\
891.2 \pm 24.8 \text { NSns }\end{array}$ & $\begin{array}{c}11.46 \pm 0.50 \\
18.33 \pm 0.42^{A}\end{array}$ & $\begin{array}{l}35.7 \pm 0.31 \\
37.7 \pm 0.47^{A}\end{array}$ & $\begin{array}{c}1.00 \pm 0.08 \\
1.27 \pm 0.02 \mathrm{NS}^{\mathrm{A}}\end{array}$ \\
\hline $\begin{aligned} & P k d 2+/- \\
+ & S c h 23390\end{aligned}$ & $\begin{array}{l}8 / 6 \\
8 / 6\end{array}$ & $\begin{array}{l}4.51 \pm 0.68 \\
21.5 \pm 1.44\end{array}$ & $\begin{array}{l}1.01 \pm 0.07 \\
1,01 \pm 0.07\end{array}$ & $\begin{array}{c}877.4 \pm 19.54 \text { NS } \\
844.3 \pm 7.42 \text { NS ns }\end{array}$ & $\begin{array}{c}9.84 \pm 0.50 \\
16.88 \pm 0.24^{A}\end{array}$ & $\begin{array}{c}34.84 \pm 0.50 \\
36.88 \pm 0.24^{A}\end{array}$ & $\begin{array}{c}1.00 \pm 0.07 \\
1.36 \pm 0.07 \mathrm{NS}^{\mathrm{A}}\end{array}$ \\
\hline $\mathrm{Pkd2}^{-1-}$ & $\begin{array}{l}7 / 6 \\
7 / 6\end{array}$ & $\begin{array}{l}5.5 \pm 0.79 \\
22.2 \pm 2.1\end{array}$ & $\begin{array}{l}0.94 \pm 0.14 \\
0.94 \pm 0.14\end{array}$ & $\begin{array}{c}949.0 \pm 20.70 \mathrm{NS} \\
877.0 \pm 8.28 \mathrm{NS} \mathrm{ns}\end{array}$ & $\begin{array}{c}11.6 \pm 1.21 \\
17.9 \pm 0.36^{A}\end{array}$ & $\begin{array}{l}35.36 \pm 0.23 \\
38.57 \pm 0.51^{A}\end{array}$ & $\begin{array}{c}1.00 \pm 0.16 \\
1.22 \pm 0.08 \mathrm{NS} n \mathrm{~s}\end{array}$ \\
\hline Pkd1 $1^{f l / f l}$ & $\begin{array}{l}8 / 7 \\
8 / 7\end{array}$ & $\begin{array}{l}6.14 \pm 0.61 \\
23.3 \pm 1.37\end{array}$ & $\begin{array}{l}1.04 \pm 0.06 \\
1.04 \pm 0.06\end{array}$ & $\begin{array}{c}884.8 \pm 6.25 \\
894.8 \pm 8.38 \mathrm{~ns}\end{array}$ & $\begin{array}{l}10.94 \pm 0.39 \\
17.03 \pm 0.33^{A}\end{array}$ & $\begin{array}{c}35.31 \pm 0.20 \\
37.81 \pm 0.20^{A}\end{array}$ & $\begin{array}{c}1.00 \pm 0.02 \\
1.30 \pm 0.05^{\mathrm{B}}\end{array}$ \\
\hline Pkd1 1/- & $\begin{array}{l}14 / 8 \\
14 / 8\end{array}$ & $\begin{array}{c}5.2 \pm 0.37 \\
20.5 \pm 0.63\end{array}$ & $\begin{array}{l}0.82 \pm 0.02 \\
0.82 \pm 0.02\end{array}$ & $\begin{array}{c}832.4 \pm 29.4 \\
826.1 \pm 18.53 N \text { Nns }\end{array}$ & $\begin{array}{c}10.63 \pm 0.17 \\
17.59 \pm 0.09^{A}\end{array}$ & $\begin{array}{c}34.20 \pm 0.53 \\
36.88 \pm 0.34^{A}\end{array}$ & $\begin{array}{c}1.00 \pm 0.06 \\
1.27 \pm 0.05 \mathrm{NS}^{\mathrm{A}}\end{array}$ \\
\hline
\end{tabular}

Values are mean $\pm \mathrm{SEM} ; N / N$, number of perfused tubules/number of mice; $\mathrm{V}_{0}$, original perfusion rate; $\mathrm{L}$, tubular length; Volume, (cell volume) formula is: $\pi \times(O D / 2)^{2} \times 1-\pi \times(I D / 2)^{2} \times 1$. The number 1 indicates the length or height is $1 \mu \mathrm{m}$. ID, inner tubular diameter; OD, outer tubular diameter; $T$, total torque; $\mathrm{Tr}$, torque measured at the perfusion rate of $5 \mathrm{~nL} / \mathrm{min}$. $\mathrm{ns}$, not significantly different from low flow rate in the same group (by $t$ test); ${ }^{A} P<0.01$; ${ }^{\mathrm{B}} P<0.001$; by $t$ test. NS, not significantly different compared with control at the similar flow rates (by ANOVA). $P k d 2$ WT and $P k d 2^{+/-}$mice were produced

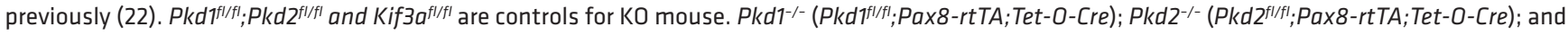
Kif3a $a^{-/-}\left(\right.$Kif3a ${ }^{f l / f l} ;$ Pax8-rtTA;Tet-O-Cre). These mice were used 2 weeks after induction with doxycycline from p28 to p42 (20).

cystic index were analyzed and compared among noncystic control, treated, and untreated $P k d 2^{-1-}$ kidneys. As shown in Figure 4, the kidney weight/body weight ratio, cystic index, and BUN were elevated in the untreated $\mathrm{Pkd2}^{---}$group compared with the noncystic group. In contrast, the DA1 antagonist SCH 23390 reduced kidney weight/body weight ratio, cystic index, and BUN in $P k d 2^{-1-}$ mice. The cystic index was reduced by $38 \%(P<0.05)$ in treated compared with the untreated $P k d 2^{-1-}$ mice. We also compared the sex differences in response to the SCH23390. As shown in Figure 4, both treated male and female mice had the same reductions on the kidney weight/body weight ratio, cystic index, and BUN compared with untreated mice. Supplemental Figure 1 (supplemental material available online with this article; https:// doi.org/10.1172/jci.insight.146041DS1) shows kidney images from all kidney histological sections used in Figure 4. The kidney images showed no cysts in the control, while many cysts formed and the kidney size was enlarged in $\mathrm{Pkd}^{-/-}$untreated kidneys. Treated mice had less cystic burden.

Figure 5 shows kidney slices with H\&E staining and immunofluorescence (IF) staining with segmental specific markers of FITC-lotus tetragonolobus agglutinin (LTA); Tamm Horsfall (THP); Calbidinand-conjugated Dolichos biflorus agglutinin (DBA) to identify PT, loop of Henle (LH), Distal convoluted tubule (DCT), and collecting duct. H\&E staining shows many tubule cysts and dilated tubules in the untreated kidney section. In contrast, there were only dilated tubules and no large cysts formed in the treated $P k d 2^{-1-}$ mouse kidney. IF staining with segment-specific markers indicated that dilated tubules and cysts exist in all segments of kidney tubules, and SCH23390 reduced tubule dilation and cysts, formed likely from all segments of the tubules. The reductions are more clearly observed in PT, collecting duct, and DCT.

Effect of dopamine receptor antagonist on renal cyst formation in Pkd1-KO mice. Because SCH23390 blocked the DA1 receptor and also blocked dopamine-stimulated adenylate cyclase (26), inhibition of cAMP signaling may reduce cyst formation (27). To further investigate whether $\mathrm{SCH} 23390$ reduction in cyst formation may relate to its impact on flow-dependent transport, we studied the effect of SCH23390 on cyst formation in $P k d 1^{-1-}$ in which flow effect is intact. Similar experimental procedures were applied to noncyst control $\left(P k d 1^{f / f f}\right)$ and $P k d 1^{-/-}\left(P k d 1^{f / f l} ; P a x 8-r t T A\right.$; Tet-O-Cre after 2 weeks induction by doxycycline from p28 to p42) with or without treatment with SCH23390. As shown in Figure 6, the kidney 
A

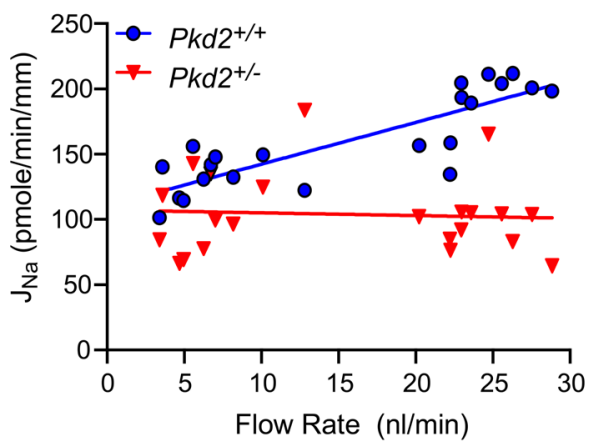

C

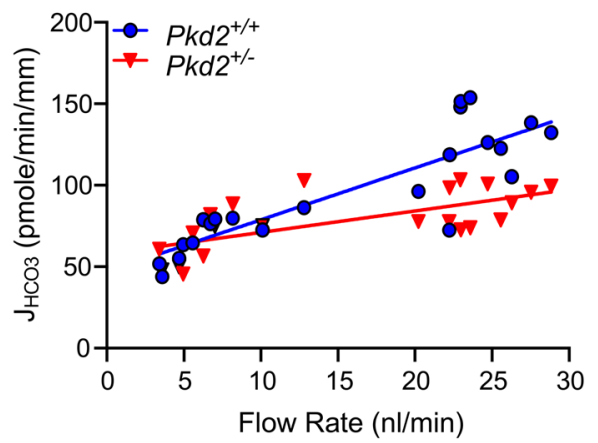

B

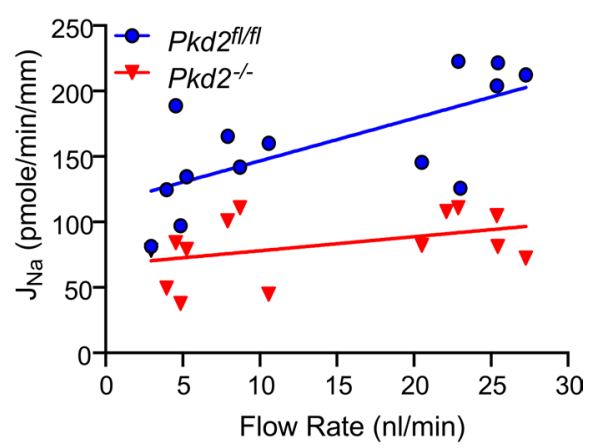

D

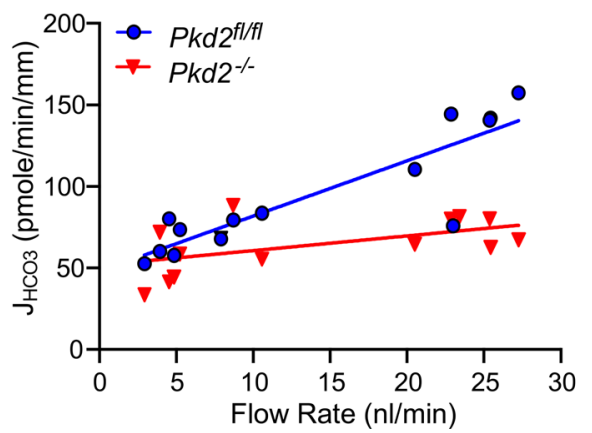

Figure 1. Flow-induced changes in $\mathrm{Na}^{+}$and $\mathrm{HCO}_{3}^{-}$absorption in $\mathbf{P k d 2}^{+-}$and $\mathrm{Pkd2}^{-/-}$mice. (A-D) Flow-induced changes in $\mathrm{Na}^{+}\left(\mathrm{J}_{\mathrm{Na}}\right)$ and $\mathrm{HCO}_{3}^{-}\left(\mathrm{J}_{\mathrm{HCO}}\right)$ absorption in control $(P k d 2 \mathrm{WT})$ and $P k d 2^{+/-}(\mathbf{A}$ and $\mathbf{C})$, and control $\left(P k d 2^{f / / 7}\right)$ and $P k d 2^{-/-}$ $\left(P k d 2^{f / f l} ;\right.$ Pax8-rtTA;Tet-O-Cre) (B and D) mice. PT were perfused in vitro, and tubular fluids were collected under low and high perfusion rates. Each point shows the mean of 3 collections of measurements from the same tubule.

image, kidney weight/body weight ratio, BUN, and cystic index had no significant reduction between treated and untreated $P k d 1^{-/-}$mice. Supplemental Figure 2 shows kidney images from all kidney histological sections used in Figure 6 that indicate no difference between treated and untreated cystic kidneys. Figure 7 shows kidney slices with $\mathrm{H} \& \mathrm{E}$ and IF staining using segmental-specific markers of LTA, THP, and DBA for identifying PT, LH, and collecting duct. H\&E staining documents the similar extent of dilated tubules and cysts in both untreated and treated $P k d 1^{-/-}$kidney sections. IF staining with segment-specific markers indicated that dilated tubules and cysts exist in all segments of kidney tubules, and SCH23390 did not change cyst distributions. We further performed power calculations using STPLAN (ver. 4.5; University of Texas, M.D. Anderson Cancer Center, Houston, Texas, USA) to investigate the possibility of SCH23390 also having an effect on Pkd1-KO mice with an increase in the number of treated mice. The results indicated that a minimum number of 720 mice would be needed for each group to obtain significant difference on BUN, kidney body weight ratio, and cystic index between control and treated groups in $P k d 1-\mathrm{KO}$ mice, as we demonstrated in $P k d 2-\mathrm{KO}$ mice. This result confirmed that $P k d 2$ and $P k d 1$ behave differently with respect to $\mathrm{SCH} 23390$ sensitivity.

Mathematical model of hydrostatic pressures within the kidney. In Figure 8 and Table 5, calculations use a kidney model to examine the impact of changes in GFR on tubule pressures. In Figure 8, both panels show luminal pressure along superficial nephrons for the whole kidney when GFR is $1.4 \mathrm{~mL} / \mathrm{min}$ and also for a 35\% increase in GFR. In the upper panel, proximal convoluted tubule flow sensitivity is maintained at baseline; in the lower panel, the sensitivity of velocity-dependent $\mathrm{Na}^{+}$reabsorption is reduced by $75 \%$. For each curve, the largest pressure drops occur in the relatively long proximal convoluted tubules and in the connecting segments, which lose luminal area as they coalesce from 36,000 nephrons to 7200 cortical collecting ducts. It is only in the case of higher GFR, with greater urine flow, that there is any sizable pressure drop along the collecting duct system. The salient observation from this figure is that, with the increase in GFR, tubular pressure goes up; with weaker GTB, this pressure increase is greater. Table 5 shows the pressures and flows that correspond to these 4 model calculations. When glomerular filtration is normal, the 2 models (baseline and reduced PT flow-dependent transport) predict nearly identical nephron pressures. 
Table 2. Flow-induced changes in sodium absorption in mouse PT

\begin{tabular}{|c|c|c|c|c|c|c|c|}
\hline \multirow[b]{2}{*}{ Group } & \multicolumn{2}{|c|}{$5 \mathrm{~nL} / \mathrm{min}$} & \multicolumn{2}{|c|}{$20 \mathrm{~nL} / \mathrm{min}$} & \multirow[b]{2}{*}{$\left(J_{\mathrm{Nab}-} J_{\mathrm{Naa}}\right)$} & \multirow[b]{2}{*}{$\Delta \mathrm{J}_{\mathrm{Na}} / \mathrm{J}_{\mathrm{Naa}} \times 100$} & \multirow{2}{*}{$\begin{array}{c}\left(\Delta \mathrm{J}_{\mathrm{Na}} / \mathrm{J}_{\mathrm{Naa}}\right) / \\
(\Delta \mathrm{T} / \mathrm{Tr})\end{array}$} \\
\hline & $n$ & $\underset{(\mathrm{pmol} / \mathrm{min} / \mathrm{mm})}{J_{\mathrm{Naa}}}$ & $n$ & $\underset{(\mathrm{pmol} / \mathrm{min} / \mathrm{mm})}{J_{\mathrm{Nab}}}$ & & & \\
\hline Pkd2 WT & 13 & $134.21 \pm 4.69$ & 13 & $197.83 \pm 6.17^{A}$ & $63.61 \pm 7.75$ & $47.40 \pm 4.59$ & $1.69 \pm 0.16$ \\
\hline $\begin{aligned} & P k d 2^{+/-} \\
+ & \operatorname{Sch} 23390\end{aligned}$ & 8 & $85.33 \pm 13.23^{D}$ & 8 & $133.82 \pm 16.5^{\mathrm{E}} B$ & $48.48 \pm 16.5$ NS & $56.82 \pm 19.3$ NS & $1.57 \pm 0.53 \mathrm{NS}$ \\
\hline$P k d 1^{f / f f l}$ & 8 & $139.84 \pm 12.83$ & 8 & $211.05 \pm 20.84^{E}$ & $71.21 \pm 24.47$ & $50.92 \pm 14.90$ & $1.70 \pm 0.50$ \\
\hline $\mathrm{Pkd1}^{-/-}$ & 14 & $134.82 \pm 11.93 N S$ & 14 & $\begin{array}{c}206.22 \pm 13.80^{A} \\
\text { NS }\end{array}$ & $71.40 \pm 18.24 \mathrm{NS}$ & $52.96 \pm 10.24 \mathrm{NS}$ & $1.96 \pm 0.38 \mathrm{NS}$ \\
\hline $\mathrm{Kif3}^{\mathrm{fl} / \mathrm{fl}}$ & 11 & $141.85 \pm 9.46$ & 11 & $209.79 \pm 14.90^{\mathrm{E}}$ & $67.94 \pm 17.65$ & $47.90 \pm 10.50$ & $1.65 \pm 0.36$ \\
\hline Kif3a-/- & 14 & $145.45 \pm 13.0 \mathrm{NS}$ & 14 & $210.58 \pm 7.77^{A}$ NS & $65.14 \pm 15.15$ NS & $44.78 \pm 5.34 \mathrm{NS}$ & $1.09 \pm 0.13 \mathrm{NS}$ \\
\hline
\end{tabular}

Values are mean \pm SEM. $N$, number of perfused tubules; $J_{\mathrm{Na}}$, the rate of sodium reabsorption; $\Delta \mathrm{J}_{\mathrm{Na}}$, the differences of $\mathrm{J}_{\mathrm{Na}}$ between low and high perfusion rate (5 and $20 \mathrm{~nL} / \mathrm{min}) ; \Delta \mathrm{J}_{\mathrm{Na}} / \mathrm{J}_{\mathrm{Nar}} \times 100$, percentage changes in sodium reabsorption from low flow rate; ns, not significantly different from low flow rates in the same group (by $t$ test); ${ }^{A} P<0.001 ;{ }^{E} P<0.05$ by $t$ test). NS, not significantly different compared with control at the similar flow rates (by ANOVA test); ${ }^{\mathrm{B}} P<0.001 ;{ }^{C} P<0.05 ;{ }^{D} P<0.01$ by ANOVA). Group of and numbers of mice used are the same as Table 1.

With the increase in GFR and urine flow, both models show higher pressures, and the pressure rise with weaker GTB is about $2 \mathrm{mmHg}$ higher. Of note, the increase in nephron pressure with greater flow is attributable to the increase generated by collecting duct hydraulic resistance. The difference in pressure from early PT to the connecting segment of about $6 \mathrm{mmHg}$ is preserved with each parameter set. In the lower half of Table 5 are simulations using the nephron model (28), in which the only compliant segments are the PT and in which the medullary interstitial conditions are unchanged from presumed antidiuretic values. With this model, the missing line in the table corresponds to the case of baseline glomerular filtration when proximal flow dependence is reduced. Under this condition, the model does not converge to a solution, since distal delivery of tubular fluid is too low to sustain tubular flow along the full nephron. For this nephron model, all urine flow rates are lower than in the kidney model, due to the hyperosmolar medulla. In the absence of strong proximal GTB, the increase in distal pressure is exaggerated.

Table 3. Flow-induced changes in bicarbonate absorption in mouse PT

\begin{tabular}{|c|c|c|c|c|c|c|c|}
\hline Group & \multicolumn{2}{|c|}{$5 \mathrm{~nL} / \mathrm{min}$} & \multicolumn{2}{|c|}{$20 \mathrm{~nL} / \mathrm{min}$} & $\left(\mathrm{J}_{\text {Hсозь- }}^{\Delta J_{\text {Hсоза }}} \stackrel{\Delta J_{\text {Hсоз }}}{ }\right)$ & $\begin{array}{l}\Delta \mathrm{J}_{\mathrm{HCO3}} / J_{\mathrm{HCO3a}} \\
\times 100\end{array}$ & $\begin{array}{c}\left(\Delta \mathrm{J}_{\mathrm{HCO3}} / J_{\mathrm{HCOza}_{2}}\right) / \\
(\Delta \mathrm{T} / \mathrm{Tr})\end{array}$ \\
\hline $\mathrm{Pkd2}^{+/-}$ & 11 & $68.60 \pm 5.51 \mathrm{NS}$ & 11 & $87.94 \pm 3.60^{\mathrm{B}, \mathrm{C}}$ & $19.33 \pm 6.58^{c}$ & $28.18 \pm 5.25^{\complement}$ & $0.91 \pm 0.17^{c}$ \\
\hline $\begin{aligned} & P k d 2^{+/-} \\
+ & S c h 23390\end{aligned}$ & 8 & $53.23 \pm 7.68 \mathrm{NS}$ & 8 & $84.41 \pm 5.53^{\mathrm{D}, \mathrm{C}}$ & $31.18 \pm 5.53^{\complement}$ & $58.58 \pm 10.39^{\mathrm{E}, \mathrm{F}}$ & $1.63 \pm 0.29^{c}$ \\
\hline$P k d 1^{f / / f l}$ & 8 & $73.18 \pm 6.55$ & 8 & $132.10 \pm 10.81^{A}$ & $58.92 \pm 12.64$ & $80.52 \pm 14.78$ & $2.68 \pm 0.49$ \\
\hline Pkd1 1/- & 14 & $67.99 \pm 4.63 \mathrm{NS}$ & 14 & $135.40 \pm 4.21^{\mathrm{A}} \mathrm{NS}$ & $67.41 \pm 6.26 \mathrm{NS}$ & $99.15 \pm 6.20 \mathrm{NS}$ & $3.67 \pm 0.23 \mathrm{NS}$ \\
\hline Kif3a $a^{f l / f l}$ & 11 & $73.33 \pm 4.74$ & 11 & $134.83 \pm 7.88^{A}$ & $61.50 \pm 9.20$ & $83.86 \pm 10.74$ & $2.89 \pm 0.37$ \\
\hline $\mathrm{Kif3a}^{-/-}$ & 14 & $67.99 \pm 4.63 \mathrm{NS}$ & 14 & $135.40 \pm 4.21^{A} \mathrm{NS}$ & $67.41 \pm 6.26 \mathrm{NS}$ & $99.15 \pm 6.20 \mathrm{NS}$ & $3.67 \pm 0.23 \mathrm{NS}$ \\
\hline
\end{tabular}

Values are mean $\pm \mathrm{SEM}$. $N$, number of perfused tubules; $J_{\text {нсоз }}$, bicarbonate absorption; $\Delta \mathrm{J}_{\mathrm{HCO}}$, the differences in $J_{\text {Hсоз }}$ between perfusion rate of 5 and $20 \mathrm{~nL} / \mathrm{min} ; \Delta \mathrm{J}_{\text {нсоз }} / \mathrm{J}_{\text {нсоза }} \times 100$, percentage changes in bicarbonate reabsorption from low flow rate; $\mathrm{ns}$, not significantly different from low flow rates in the same group (by $t$ test); ${ }^{A} P<0.001 ;{ }^{\mathrm{B}} P<0.01 ;{ }^{\mathrm{D}} P<0.05$ by $t$ test). NS, not significantly different compared with control at the similar flow rates (by ANOVA); ${ }^{\mathrm{C} P}<0.001 ;{ }^{\mathrm{E}} P<0.01$ by ANOVA). ${ }^{\mathrm{F}} P<0.05$ by $t$ test between $P k d 2^{+/-}$and $P k d 2^{+/-}+$Sch23390. Group and numbers of mice used are the same as Table 1. 
Table 4. Flow-induced changes in fluid absorption in mouse PT

\begin{tabular}{|c|c|c|c|c|c|c|c|}
\hline \multirow[t]{2}{*}{ Group } & \multicolumn{2}{|c|}{$5 \mathrm{~nL} / \mathrm{min}$} & \multicolumn{2}{|c|}{$20 \mathrm{~nL} / \mathrm{min}$} & \multirow{2}{*}{$\left(J_{v b-}^{\Delta J_{v a}}\right)$} & \multirow[t]{2}{*}{$\Delta \mathrm{J}_{\mathrm{v}} / \mathrm{J}_{\mathrm{Va}} \times 100$} & \multirow{2}{*}{$\begin{array}{c}\left(\Delta \mathrm{J}_{\mathrm{v}} / \mathrm{J}_{\mathrm{va}}\right) / \\
(\Delta \mathrm{T} / \mathrm{Tr})\end{array}$} \\
\hline & $n$ & $\frac{J_{\mathrm{Va}}}{(\mathrm{pmol} / \mathrm{min} / \mathrm{mm})}$ & $n$ & $\frac{J_{\mathrm{vb}}}{(\mathrm{pmol} / \mathrm{min} / \mathrm{mm})}$ & & & \\
\hline Pkd2 WT & 13 & $0.91 \pm 0.03$ & 13 & $1.35 \pm 0.04^{A}$ & $0.43 \pm 0.05$ & $47.40 \pm 4.59$ & $1.69 \pm 0.16$ \\
\hline $\mathrm{Pkd2}^{+/-}$ & 11 & $0.74 \pm 0.07^{\mathrm{B}}$ & 11 & $0.67 \pm 0.05 \mathrm{~ns}^{\mathrm{c}}$ & $0.07 \pm 0.09^{c}$ & $-9.29 \pm 7.19^{c}$ & $-0.30 \pm 0.23^{c}$ \\
\hline $\begin{aligned} & P k d 2^{+/-} \\
+ & S c h 23390\end{aligned}$ & 8 & $0.58 \pm 0.09^{D}$ & 8 & $0.91 \pm 0.11^{\mathrm{E}, \mathrm{C}}$ & $0.33 \pm 0.11 \mathrm{NS}$ & $56.82 \pm 19.3$ NS & $1.58 \pm 0.53 \mathrm{NS}$ \\
\hline$P k d 1^{f l / f l}$ & 8 & $0.95 \pm 0.09$ & 8 & $1.44 \pm 0.14^{\mathrm{E}}$ & $0.49 \pm 0.17$ & $50.92 \pm 14.90$ & $1.70 \pm 0.50$ \\
\hline $\mathrm{Pkd1}^{-/-}$ & 14 & $0.92 \pm 0.08$ NS & 14 & $1.41 \pm 0.09^{A} \mathrm{NS}$ & $0.49 \pm 0.12 \mathrm{NS}$ & $52.96 \pm 10.24 \mathrm{NS}$ & $1.96 \pm 0.38 \mathrm{NS}$ \\
\hline Kif3a $a^{f l / f l}$ & 11 & $0.97 \pm 0.06$ & 11 & $1.43 \pm 0.10^{\mathrm{E}}$ & $0.46 \pm 0.12$ & $47.90 \pm 10.50$ & $1.65 \pm 0.36$ \\
\hline $\mathrm{Kif3a}^{-/-}$ & 14 & $0.99 \pm 0.09$ NS & 14 & $1.44 \pm 0.05^{\mathrm{A}} \mathrm{NS}$ & $0.44 \pm 0.10 \mathrm{NS}$ & $44.78 \pm 5.34 \mathrm{NS}$ & $1.09 \pm 0.13 \mathrm{NS}$ \\
\hline
\end{tabular}

Values are mean $\pm \mathrm{SEM} . \mathrm{N}$, number of perfused tubules; $J_{v}$, fluid absorption; $\Delta \mathrm{J}_{\mathrm{v}}$, the differences in $\mathrm{J}_{\mathrm{v}}$ between perfusion rate of $5 \mathrm{and} 20 \mathrm{~nL} / \mathrm{min} ; \Delta \mathrm{J}_{\mathrm{V}} / \mathrm{J}_{\mathrm{Va}} \times$ 100 , percentage changes in fluid reabsorption from low flow rate; ns, not significantly different from low flow rates in the same group, by $t$ test; ${ }^{A} P<0.001$; ${ }^{E} P<0.05$ by $t$ test). NS, not significantly different compared with control at the similar flow rates (by ANOVA); ${ }^{B} P<0.05 ;{ }^{C} P<0.001 ;{ }^{D} P<0.01$ by $A N O V A$ ). Group and numbers of mice used are the same as Table $1 . J_{V a}, J_{v}$ at the low flow rate; $J_{V b}, J_{v}$ at the high flow rate.

\section{Discussion}

The physiological importance of flow-dependent PT transport, or GTB, has been recognized for its role in the maintenance of body fluid and electrolyte homeostasis for more than 4 decades $(1,2)$. In mathematical models of rat kidney, increases in GFR increase intratubular hydrostatic pressures along the nephron; with impaired GTB, these increases in tubule pressure are more severe, in both proximal and distal segments. Mathematical models of the kidney have suggested that GTB may also mitigate swings in renal tubular hydrostatic pressure. In this study, we find that - prior to cyst formation - flow-dependent transport is absent in PT from $\mathrm{Pkd2}^{-{ }^{--}}$mice and that flow dependence can be restored by a dopamine antagonist. In $P k d 2^{-1-}$ mice aged to allow for cyst formation, chronic administration of an oral dopamine antagonist slowed renal cyst formation; this did not occur

A

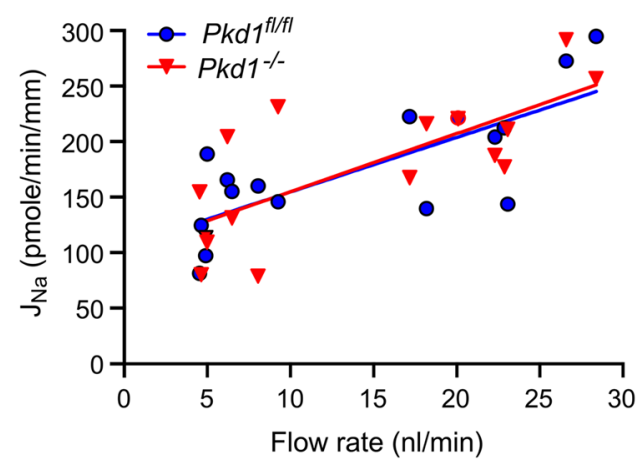

C

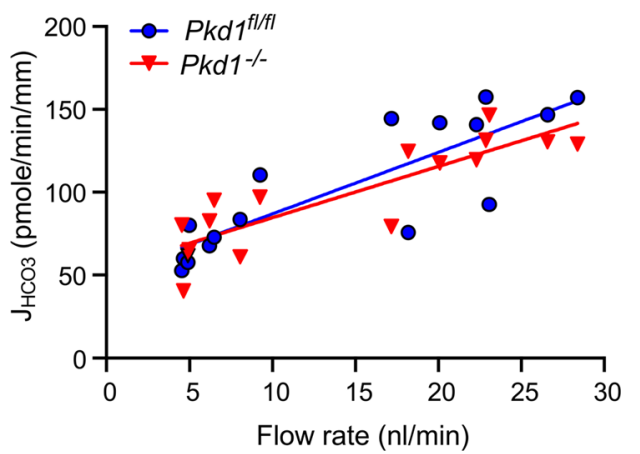

B

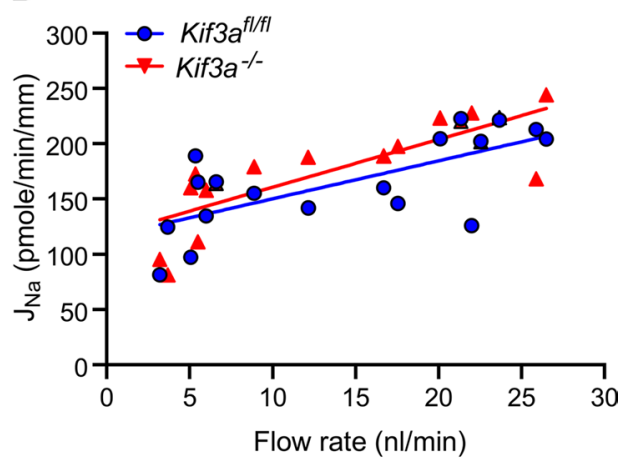

D

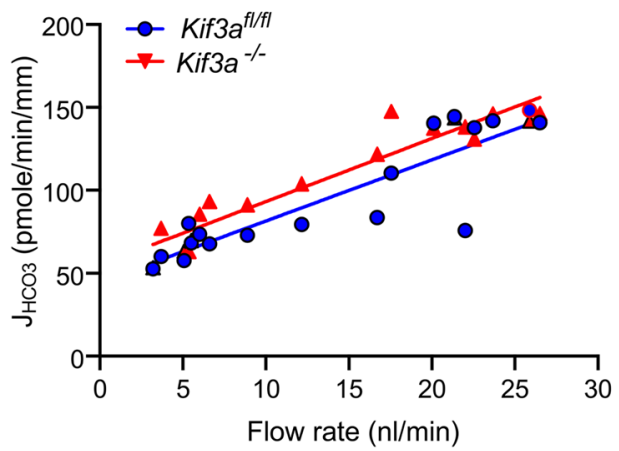

Figure 2. Flow-induced changes in $\mathrm{Na}^{+}$and $\mathrm{HCO}_{3}{ }^{-}$absorption in Pkd1 $^{-/-}$and $\mathrm{Kif3a}^{-/-}$mice. (A-D) Flow-induced changes in $\mathrm{Na}^{+}$ $\left(J_{\mathrm{Na}}\right)$ and $\mathrm{HCO}_{3}^{-}\left(\mathrm{J}_{\mathrm{HCO}}\right)$ absorption in control $\left(P k d f^{f / f}\right)$ and $P k d^{-1}$ (Pkd fl/fi):Pax8-rtTA;Tet-O-Cre) (A and $\mathbf{C})$, and control (Kif3a $\left.a^{f / f l}\right)$ and Kif3a- ${ }^{-1-}$ (Kif3a ${ }^{f / f f} ;$ Pax8-rtTA; Tet-O-Cre) (B and D) mice. PT were perfused in vitro, and tubular fluids were collected under low and high perfusion rates. Each point shows the mean of 3 collections of measurements from the same tubule. 
A

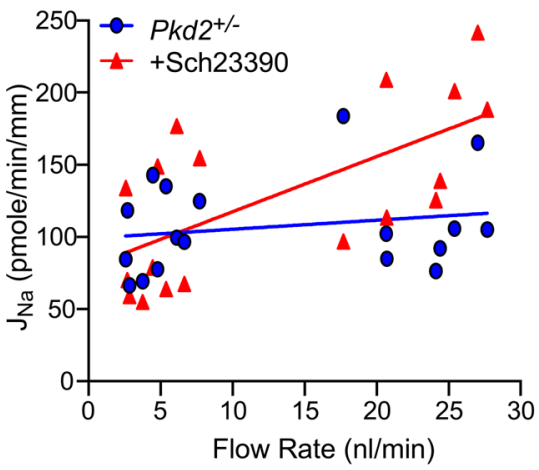

C

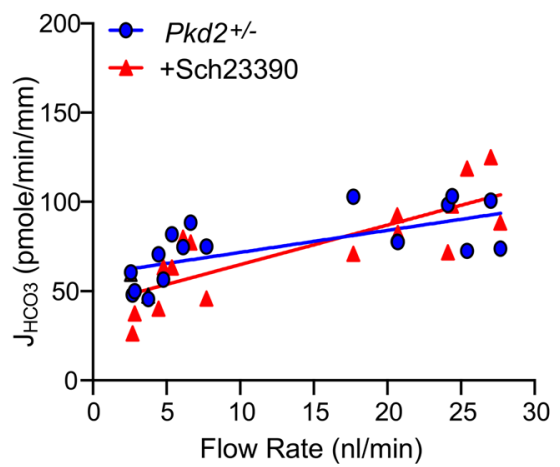

B

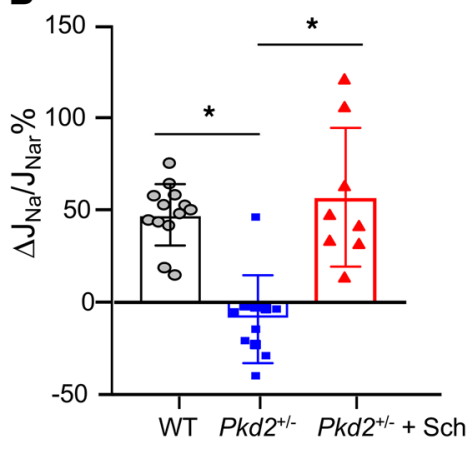

D

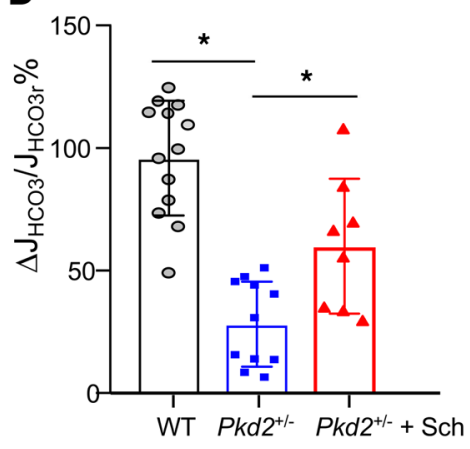

E

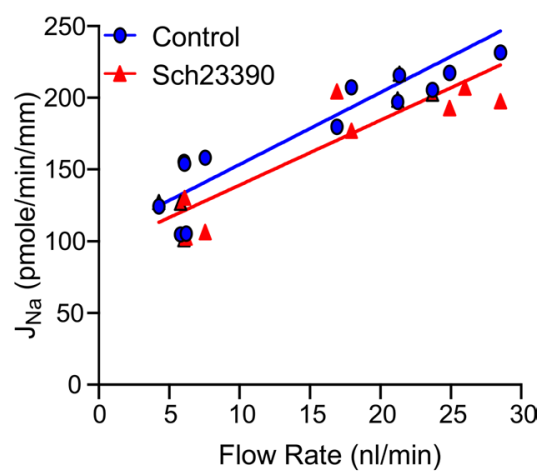

$\mathbf{F}$

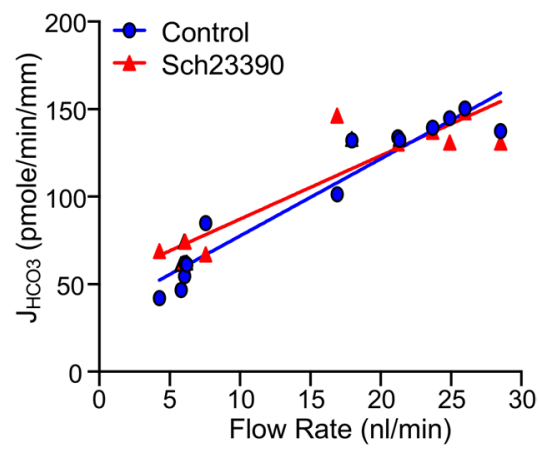

Figure 3. Effect of the dopamine receptor antagonist $\mathbf{S C H} 2339$ on flow-stimulated $\mathrm{Na}^{+}$and $\mathrm{HCO}_{3}{ }^{-}$absorption. Effect of the dopamine receptor antagonist SCH23390 on flow-stimulated $\mathrm{Na}^{+}\left(\mathrm{J}_{\mathrm{Na}}\right)$ and $\mathrm{HCO}_{3}^{-}\left(\mathrm{J}_{\mathrm{HCO}}\right)$ absorption in control ( $P k d 2 \mathrm{WT}$ ) and $\mathrm{Pkd2}^{+-}$mice. PT were perfused in vitro, and tubular fluids were collected under low and high perfusion rates. (A, C, E, and F) SCH23390 $\left(1 \times 10^{-5} \mathrm{M}\right)$ was added to the luminal perfusate in $P k d 2^{+/-}$mice $(\mathbf{A}$ and $\mathbf{C})$ in $\mathbf{W T}$ mice (E and $\mathbf{F})$. (B and $\mathbf{D}) \Delta \mathrm{J}_{\mathrm{Na}} / \mathrm{J}_{\mathrm{Nar}} \%$ is the fractional change of differences of high flow rate $(20 \mathrm{~nL} / \mathrm{min})$ from low flow rate $\left(r=5 \mathrm{~nL} / \mathrm{min}^{2}\right)$ of $\mathrm{Na}^{+}$and $\mathrm{HCO}_{3}{ }^{-}$ absorption. ${ }^{*} P<0.05$ by 1 -way ANOVA; data are presented as the mean $\pm \mathrm{SEM}$. $\mathrm{J}_{\mathrm{Nar}} \mathrm{J}_{\mathrm{Na}}$ at low flow rate $(r=5 \mathrm{~nL} / \mathrm{min})$.

in $P k d 1^{-1}$, which retained intact GTB in the precystic state. Our findings suggest that there may be differences in therapeutic approach to the 2 forms of PKD. Based on our examination of $\mathrm{Kif3a}^{-1-}$ tubules, we also demonstrate that cilia are not a prerequisite for GTB.

Multiple mechanisms may be involved in renal cyst formation in PKD. It has been found that inactivation of $P k d 1$ or an essential IFT gene, tg737 (IFT88) in adult mice results in no cyst formation until months after deletion of either gene $(29,30)$. Although deletion of $P k d 1, P k d 2$, or $K I f 3 a$ (required for cilia formation) produces renal cysts, with progressive enlargement of fluid-filled renal cysts when the disease reaches the late stage, different mechanisms are involved in cystic development and formation with $P k d 1$, $P k d 2$, and Kif3a mutations that may be due to differences in localization and functions within in the kidney (20). However, one similarity is that $P k d 1, P k d 2$, and Kif3a are all implicated in mechanosensory or chemosensory functions (10). $P k d 1$ and $P k d 2$ are expressed in primary cilia, and primary cilia play an important role in mechanosensory function responding to flow-induced changes of calcium signals in MDCK cells and in the cortical collecting duct $(4,16,17)$. Whether $P k d 1$ and $P k d 2$ or primary cilia have a functional role of flow sensing mechanism in regulation of GTB in the PT has never been studied. Because complete genetic KO of $P k d 1$ or $P k d 2$ in mice results in embryonic lethality (22), we have used

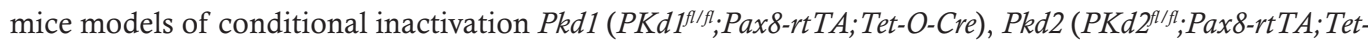

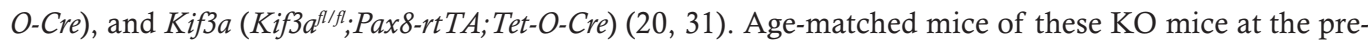
cystic stage were used to measure flow-activated $\mathrm{Na}$ and $\mathrm{HCO}_{3}^{-}$absorption in $\mathrm{PT}$ by microperfusion. In addition, the age-matched WT and Pkd2 heterozygous mice (22) were also used for the microperfusion study. Experimental data show that the flow-stimulated $\mathrm{Na}^{+}$and $\mathrm{HCO}_{3}{ }^{-}$absorptions are preserved in Pkd1 (Pkd1 ${ }^{f / f} ;$ Pax8-rtTA;Tet-O-Cre) and Kif3a (Kif3a ${ }^{f / f} ;$ Pax8-rtTA;Tet-O-Cre) mice, indicating that neither $P k d 1$ or primary cilia are critical for flow sensing in PT. This result also suggests that neither intact PC1 nor the primary cilia are required for mechanosensory function in the PT. Our observed dissociation of flow-dependent transport and intact cilia in PT (Kif3a experiments) is consistent with findings in 
A

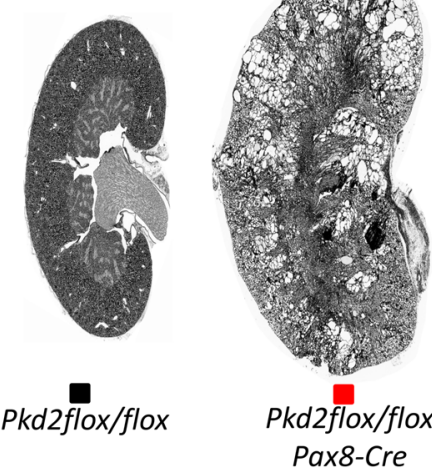

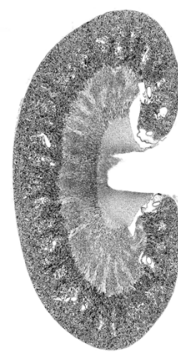

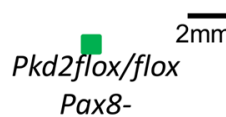

Cre; Treatment
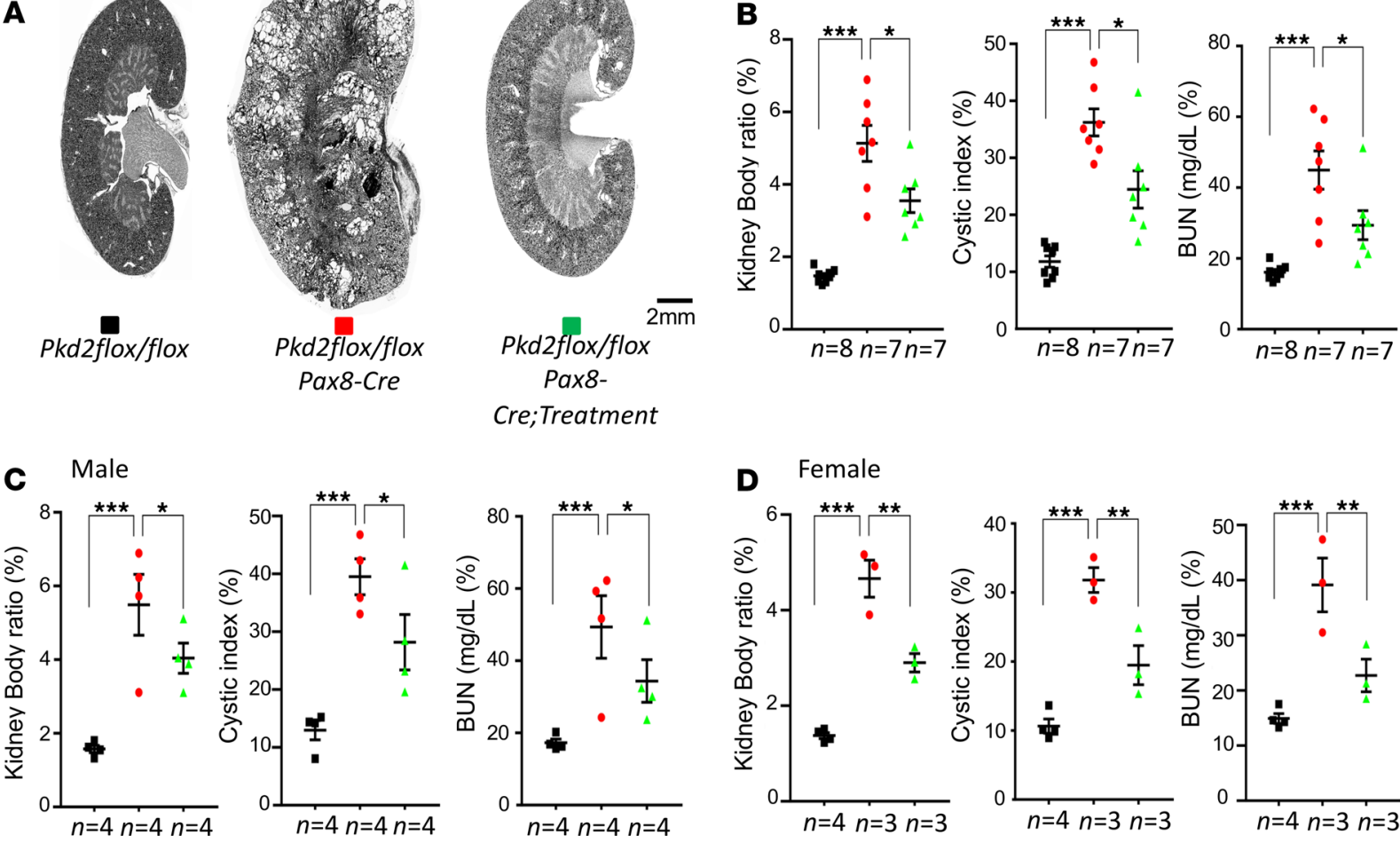

D Female
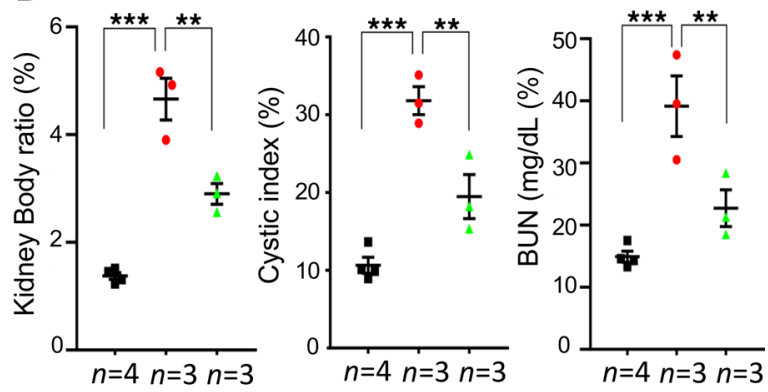

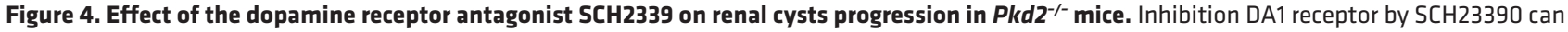
reduce cyst formation in an adult-onset autosomal dominant polycystic kidney disease model with selective inactivation of $P k d 2$. (A) Images of representative kidneys from adult-onset KO model (Pax8 rtTA; Teto-Cre) with the indicated genotypes at 18 weeks. (B) Aggregate data of the kidney weight/body weight ratio, cystic index, and BUN from the indicated number of mice. (C) Aggregate data of the kidney weight/body weight ratio, cystic index, and BUN from the indicated number of male mice. (D) Aggregate data of the kidney weight/body weight ratio, cystic index, and BUN from the indicated number of female mice. The color blocks in A correspond to the data in B-D. The numbers of animals $(n)$ in each group are indicated below the histogram bars. Multiple group comparisons were performed using 1-way ANOVA, followed by Tukey's multiple comparison test; data are presented as the mean \pm SEM.

distal nephron segments, specifically preservation of flow-dependent $\mathrm{Na}^{+}$reabsorption in the deciliated cortical collecting duct (32) and failure to observe flow-dependent $\mathrm{Ca}^{2+}$ responses in superfused inner medullary collecting ducts (33).

Experimental data demonstrate the absence of flow-stimulated $\mathrm{Na}^{+}$and $\mathrm{HCO}_{3}{ }^{-}$in both $\mathrm{Pkd} 2^{+/-}$and $\mathrm{Pkd}^{-/-}\left(\mathrm{Pkd} 2^{f l f f} ; \mathrm{Pax} 8-r t T A ; T e t-O-C r e\right.$ Pax8-rtTA) mice. The findings of this study suggest that the role of PC2 in flow-dependent transport derives from its functions outside the primary cilium. PC2, formerly TRPP2 encoded by $P k d 2$, is a calcium-activated cation channel expressed in the primary cilia, as well as in other compartments of the cell, including the endoplasmic reticulum (ER) (11). Previous studies showed that $P k d 2$ mutation or KO resulted in an absence of IP3 receptor-mediated calcium release from the ER, indicating that PC2 plays an important role in IP3 receptor-mediated calcium signaling (12). We have demonstrated that IP3 receptor-mediated intracellular $\mathrm{Ca}^{2+}$ signaling plays a critical role in transduction of microvillus torque to increase $\mathrm{Na}^{+}$and $\mathrm{HCO}_{3}^{-}$absorption in PT (21). The new observation of absence of GTB in $P k d 2^{+/-}$and in $P k d 2^{---}$mice could further derive from the functional role of $P k d 2$ as the IP3 receptor-mediated TRPP2 channel in the ER (11). Alternatively, we have shown that intact cytoskeletal function is a prerequisite for flow-dependent transport in $\operatorname{PT}(3,5)$. It is also known that there are structural connections between PC2 and cytoskeletal components (34). It is possible that the absence of $\mathrm{PC} 2$, or the presence of defective $\mathrm{PC} 2$, may compromise the signal transduction function of the actin cytoskeleton. If this were the mechanism underlying our observations, one might not see a functional difference between the $P k d 2$ homozygote and heterozygote.

Motivation for these studies was derived, in part, from model calculations in a model of rat nephrons (28). In that model, a full ensemble of superficial and juxtamedullary nephrons fed into connecting segments, which coalesced into the collecting duct system. It was observed that variation in PT glucose 
Pkd2 flox/flox;Pax8-Cre

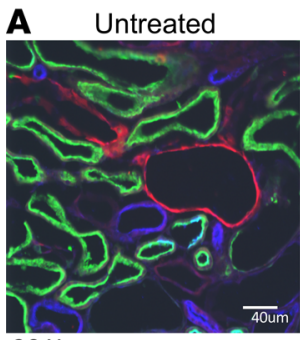

$20 x$

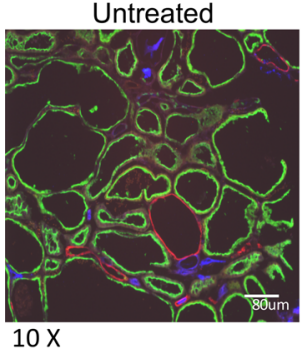

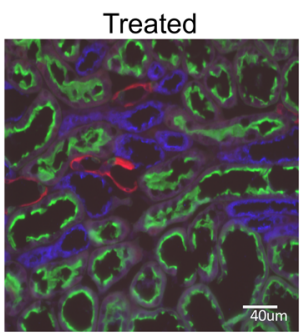

DBA/LTA/THP

Treated

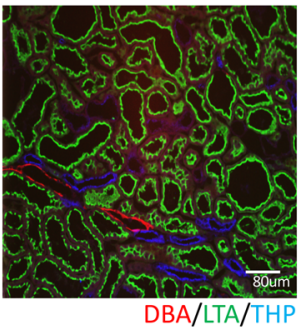

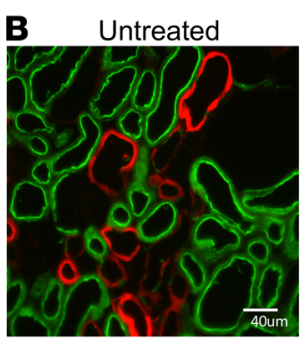

$20 \mathrm{X}$

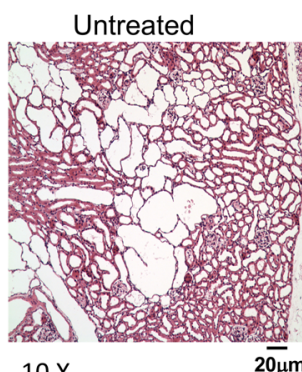

$10 x$
Pkd2 flox/flox;Pax8-Cre

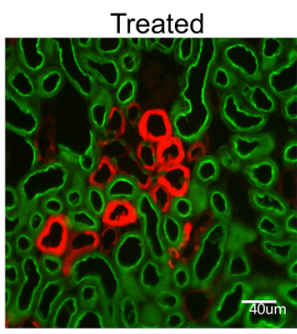

Calbidin/LTA

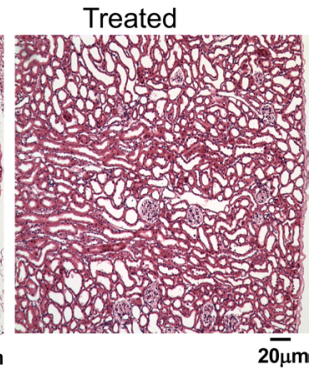

Figure 5. Kidney slices with HE staining and IF staining with nephron segmental-specific markers to identify PT, LH, DCT, and CD. (A) IF with Rhodamine-conjugated Dolichos biflorus agglutinin (DBA) (red), FITC-lotus tetragonolobus agglutinin (LTA) (green), and sheep anti-tamm horsfall glycoprotein antibody (blue). (B) IF with mouse anti-calbidin (red) and FITC-LTA (green). (C). Polycystin-2 expression in PT of WT mouse kidney demonstrated with IF staining of rabbit anti-polycystin-2 (green) and FITC-LTA (green). Kidney sections were from 18-week-old adult

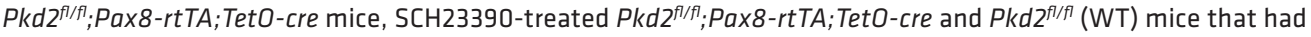
received doxycycline induction from $\mathrm{P} 28$ to $\mathrm{P} 42$.

reabsorption augmented or reduced distal flow, which in turn produced parallel changes in tubule pressures along the whole nephron, extending back to early PT (28). In that model, the PT was compliant, and proximal $\mathrm{Na}^{+}$reabsorption was directly dependent upon luminal fluid velocity (23). Increased PT pressure with greater distal delivery, which has support in micropuncture observations in rat (35), found that acetazolamide increased LH delivery by $44 \%$ and urine flow 5-fold; with that, PT pressure increased from 13.6 to $15.6 \mathrm{mmHg}$. Those nephron model calculations suggested that, with defective flow-dependent proximal $\mathrm{Na}^{+}$reabsorption, normal episodic increases in GFR might provoke larger swings in tubule pressure. It was speculated that such increases in tubular hydrostatic pressure might contribute to the creation and growth of renal cysts, analogous to the role of arterial pressure in creating vascular aneurysms.

The hypothesis generated by the nephron model was subject to at least 2 limitations: (a) medullary composition and pressure had been assigned so that interstitial pressure changes were not computed and (b) the only compliant nephron segments of that model were the proximal convoluted tubules. The first concern was addressed with creation of a kidney model, which included the medullary vasculature and, thus, enabled calculation of medullary interstitial conditions (36). Tubule compliance along all segments was introduced in a revision to that model (37). It must be acknowledged that the experimental data guiding assignment of tubule compliance were scant, with few studies in rat PT (38-40) and 1 regarding rat distal tubule (38). Nevertheless, in the kidney model's simulation of a 35\% increase in glomerular filtration, a 75\% reduction in proximal flow sensitivity produced a $30 \%$ increase in both proximal and distal pressures (Table 5). In the noncompliant nephron model, the increase in tubule pressures was about $50 \%$. These model observations provided the rationale for examining the dopamine antagonist SCH23390, which had been shown to enhance PT flow-dependent $\mathrm{Na}^{+}$reabsorption (8), in order to see whether it might mitigate cyst growth in $\mathrm{PKD}$.

Dopamine is the most important natriuretic signal to PT $(41,42)$. It acutely decreases surface NHE3 expression in opossum kidney (OK) cells and stimulates NHE3 endocytosis in PT (24). These effects depend on the DA1 receptor- and DA2 receptor-mediated protein kinase A (PKA) (24). A prior study of the perfusion of isolated rabbit tubules reported that dopamine had no effect on PT transport in unstimulated conditions but abolished the norepinephrine-induced increase in $\mathrm{Na}^{+}$absorption (25). This observation is consistent with our data showing that dopamine had no effect on NHE3 activity at low flow rates but abolished the flow-stimulated $\mathrm{Na}$ absorption and partially inhibited the flow-stimulated $\mathrm{HCO}_{3}^{-}$absorption (8). In this study, 
Figure 6. Effect of the dopamine receptor antagonist SCH2339 on renal cysts progression in Pkd1/- mice. Inhibition DA1 receptor by SCH23390 has no effect on cyst progression in adult-onset autosomal dominant polycystic kidney disease model with selective inactivation of $P k d 1$. (A) Images of representative kidneys from adult-onset $\mathrm{KO}$ model (Pax8 rtTA; Teto-Cre) with the indicated genotypes at 18 weeks. (B) Aggregate data of the kidney weight/ body weight ratio, cystic index, and BUN from the indicated number of mice. The color blocks in $\mathbf{A}$ correspond to the data in $\mathbf{B}$. The numbers of animals ( $n$ ) in each group are indicated below the histogram bars. Multiple group comparisons were performed using 1-way ANOVA followed by Tukey's multiple comparison test and are presented as the mean \pm SEM.
A
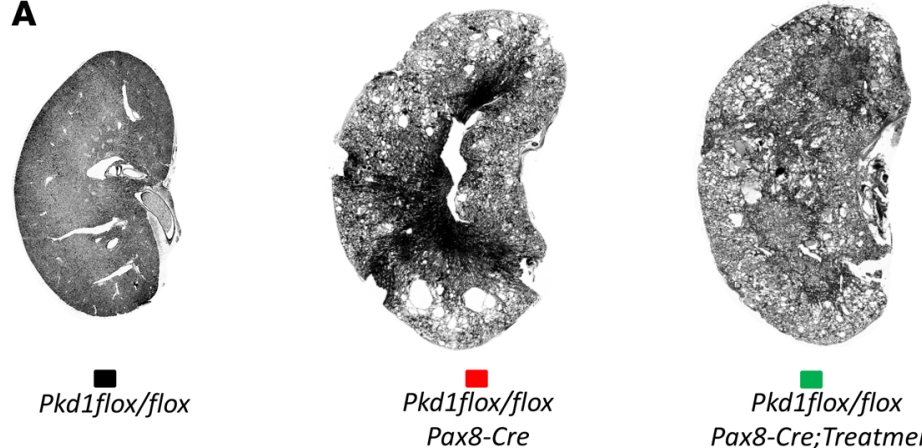

Pkd1flox/flox Pax8-Cre;Treatment
B

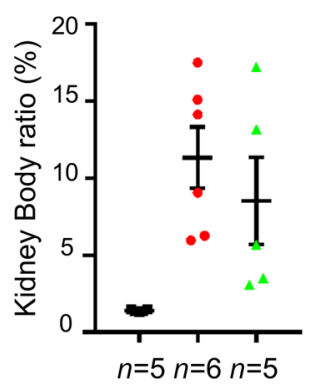

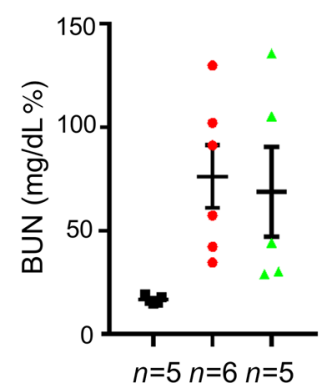

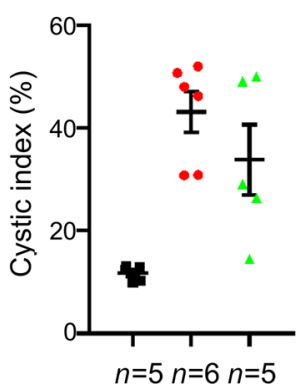

we provide evidence that impaired GTB can occur before renal cystic formed and increased the tubule sensitive to flow by a DA1 antagonist, slowing the renal cyst formation in $P k d 2 \mathrm{KO}$ mice. In the case of $P k d 1$ or Kif3a mice, there was no abnormality in flow-dependent regulation of PT transport, and SCH23390 had no salutary effect on cyst formation. It must be acknowledged that this study has not provided proof that the cyst protection afforded by SCH23390 derived from its effect on PT, just that its PT action motivated our decision to try it as a therapeutic. It must also be acknowledged that we have not provided measurement of the critical variable in the hypothesis that episodically elevated tubule hydrostatic pressures play pathophysiologic roles in the cyst formation of $P k d 2$. At this point, it is not clear how such data could be obtained.

Common pathogenic mechanisms of the Autosomal Dominant Polycystic Kidney Disease (ADPKD) - caused by mutations in $P k d 1$ or $P k d 2$, including disruption of intracellular calcium homeostasis, excessive cell proliferation and fluid secretion, abnormal extracellular matrix, and disruption of mechanisms controlling tubular diameter - contribute to cyst formation (43). There was no specific difference in these

A Pkd1flox/flox;Pax8-Cre; Untreated
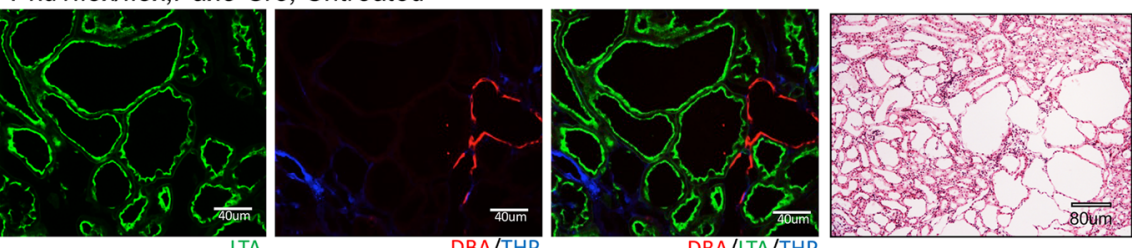

B
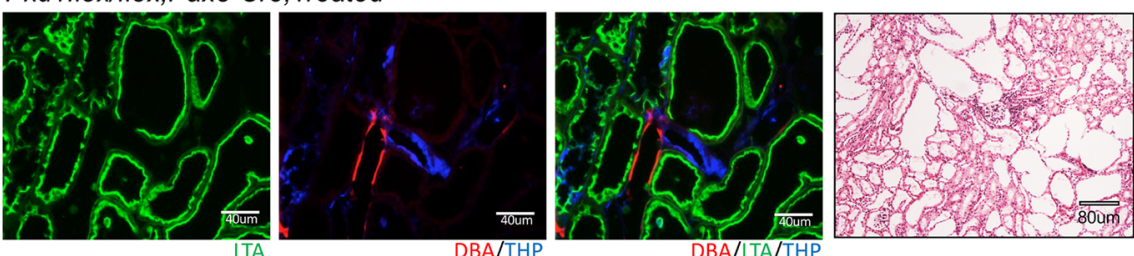

Figure 7. Kidney slices with HE staining and IF staining. IF with Rhodamine-conjugated Dolichos biflorus agglutinin (DBA) (red), FITC-LTA (green), and Sheep anti-tamm horsfall glycoprotein antibody (blue). Kidney sections were from 18-week-old adult Pkdff/fl; Pax8-rtTA;TetO-cre mice and SCH23390-treated Pkd $7^{f / f / f}$;Pax8-rtTA;TetO-cre mice that had received doxycycline induction from P28 to P42. 

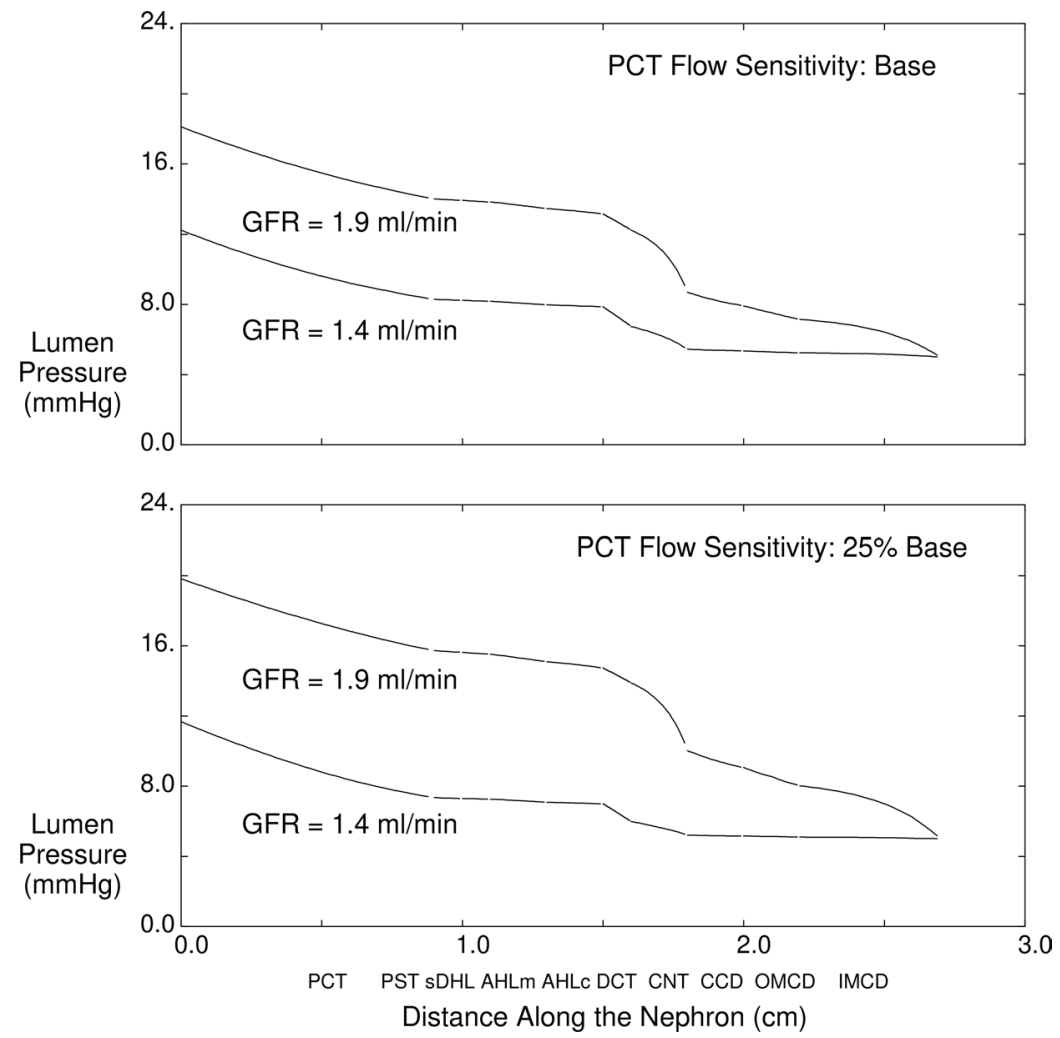

Figure 8. Model calculations of the impact of changes in GFR on tubule press. The abscissa is the distance along the superficial nephrons, with the first $9 \mathrm{~mm}$ corresponding to proximal convoluted tubule. The next $4 \mathrm{~mm}$ include proximal straight tubule, short descending Henle limb, and medullary ascending Henle limb. The next $3 \mathrm{~mm}$ are cortical ascending Henle limb and distal convoluted tubule. Then, there is a $2 \mathrm{~mm}$ connecting segment and, finally, $9 \mathrm{~mm}$ of the collecting ducts, from cortex to papilla. Both panels show luminal pressure along superficial nephrons for whole kidney when GFR is $1.4 \mathrm{~mL} / \mathrm{min}$ and also for a $35 \%$ increase in GFR. In the upper panel, proximal convoluted tubule flow sensitivity is maintained at baseline; in the lower panel, the sensitivity of velocity-dependent $\mathrm{Na}^{+}$reabsorption is reduced by $75 \%$.

common pathogenic mechanisms for $P k d 1$ or $P k d 2$ mutation-caused ADPKD. Our study suggests a potentially new pathogenic phenotype of $P k d 2$ deletion - namely, a pattern of chronic episodic tubule dilatation in response to swings of luminal hydrostatic pressure.

\section{Methods}

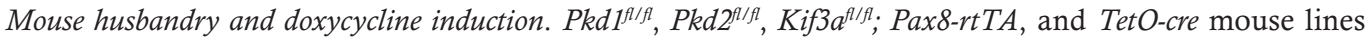
have been described previously (20). Since all 3 animal models are well characterized, the methods of produce control and KO mice were carefully followed as described previously (20). Mouse lines in this study that used Pax8-rtTA; TetO-cre transgenic system for gene deletion were administered doxycycline for 2 weeks, beginning at P28 for adult induction. Doxycycline solution was made from drinking water supplemented with $2 \mathrm{mg} / \mathrm{mL}$ doxycycline hyclate (D9891; MilliporeSigma) and 3\% sucrose (S-0389; MilliporeSigma). Animals treated at P28 were switched from regular drinking water to doxycycline solution for 2 weeks and then returned to regular drinking water until the study end point.

At the study end points, mice were euthanized, and kidneys and serum were collected as described previously. $P k d 2$ was inactivated by inserting a selectable neo ${ }^{r}$ cassette into the Not $\mathrm{I}$ site at codon 59 in exon 1 in the same transcriptional orientation as $P k d 2(22)$.

Microperfusion of kidney PT. Eight- to nine-week-old mice (male and female) were used for microperfusion in vitro. A standard method for isolated tubule perfusion was used as described previously (5). Briefly, animals were anesthetized with i.p. sodium pentobarbital $100 \mathrm{mg} / \mathrm{kg}$, and freshly dissected PT were perfused with an ultrafiltrate-like solution containing (in mM) $125 \mathrm{NaCl}, 25 \mathrm{NaHCO}_{3}, 1$ $\mathrm{CaCl}_{2}, 1.2 \mathrm{MgSO}_{4}, 2$ glutamine, 2 lactic acid, 5 glucose, $5 \mathrm{KCl}$, and 1.2 phosphoric acid. Extensively dialyzed $\left[{ }^{3} \mathrm{H}\right]$-methoxy-inulin was added to the luminal perfusate at a concentration of $30 \mu \mathrm{Ci} / \mathrm{mL}$ as 
Table 5. The impact of changes in GFR on tubule pressures

\begin{tabular}{|c|c|c|c|c|c|c|c|c|}
\hline \multicolumn{9}{|c|}{ Kidney model flows and pressures } \\
\hline \multicolumn{7}{|c|}{ Whole-kidney flow ( $\mu \mathrm{L} / \mathrm{min})$} & \multicolumn{2}{|c|}{ Pressure $(\mathrm{mmHg})$} \\
\hline GFR & End SFPCT & FPR & Initial CNT & End IMCD & FDD & FUO & Initial SFPCT & Initial CNT \\
\hline 720.0 & 231.2 & $68 \%$ & 219.7 & 27.9 & $15 \%$ & $1.9 \%$ & 12.2 & 6.7 \\
\hline 972.0 & 378.1 & $61 \%$ & 599.3 & 292.9 & $31 \%$ & $15.1 \%$ & 18.1 & 12.2 \\
\hline \multicolumn{9}{|c|}{ PCT flow sensitivity is reduced $75 \%$} \\
\hline \multicolumn{9}{|c|}{ Nephron model flows and pressures } \\
\hline \multicolumn{7}{|c|}{ Whole-kidney flow $(\mu \mathrm{L} / \mathrm{min})$} & \multicolumn{2}{|c|}{ Pressure $(\mathrm{mmHg})$} \\
\hline GFR & End SFPCT & FPR & Initial CNT & End IMCD & FDD & FUO & Initial SFPCT & Initial CNT \\
\hline \multicolumn{9}{|c|}{ GTB is at baseline } \\
\hline 720.0 & 250.0 & $65 \%$ & 138.8 & 2.1 & $10 \%$ & $0.1 \%$ & 11.5 & 6.9 \\
\hline
\end{tabular}

SFPCT, superficial proximal convoluted tubule; CNT, connecting segment; IMCD, inner medullary collecting duct; FPR, fractional proximal reabsorption; FDD, fractional distal delivery (initial CNT flow relative to twice the initial SFPCT flow); FUO, fractional urine output (end IMCD flow relative to twice the initial SFPCT flow). With reduction in flow sensitivity of PT, there is a much wider swing in FPR, which falls with higher GFR, 7\% at baseline and 17\% with reduced flow sensitivity. These differences in proximal reabsorption translate into a respective doubling and tripling of delivery to the connecting segment (FDD) and an 8-fold versus 30-fold increase in urine output with the increase in filtration. These changes in collecting duct urine flow translate into differences in nephron pressures. The solution of the model pressures is predicated on the assumption of ureteral hydrostatic pressure of $5 \mathrm{mmHg}$ in all simulations (37).

a volume marker. The bath solution contained similar electrolytes as the luminal solution, with added $3 \mathrm{~g} / \mathrm{dL}$ albumin. The perfusate and bath solutions were bubbled with $95 \% \mathrm{O}_{2}-5 \% \mathrm{CO}_{2}$, the $\mathrm{pH}$ was adjusted to 7.4, and the osmolalities to $300 \mathrm{mosmol} / \mathrm{KgH}_{2} \mathrm{O}$ in both solutions. Bath fluid was continuously changed at a rate of $0.5 \mathrm{~mL} / \mathrm{min}$ to maintain the constancy of $\mathrm{pH}$ and bath osmolality. PT were perfused at either low $(5 \mathrm{~nL} / \mathrm{min})$ or high $(20 \mathrm{~nL} / \mathrm{min})$ perfusion rates, and the tubular fluid was collected (5). Three timed collections of tubular fluid were made, and ${ }^{3} \mathrm{H}$ concentrations and total $\mathrm{CO}_{2}$ concentrations in perfusate and collected sample fluid were measured; rates of fluid, $\mathrm{Na}^{+}$and $\mathrm{HCO}_{3}$ absorption were calculated by standard methods (5). The $\mathrm{J}_{\mathrm{Na}}$ was calculated according to the rate of fluid absorption $\left([\mathrm{Na}] \times \mathrm{J}_{\mathrm{v}}\right.$ ), since the ratio of fluid and $\mathrm{Na}^{+}$absorption is 1 in the PT (3).

IF and imaging. Mice were sacrificed at age of 18 weeks, and kidneys were fixed in $4 \%$ PFA for histological analysis. Sagittal sections of kidneys were processed for H\&E staining.

Renal markers used for IF were Rhodamine-conjugated DBA (1;1000 dilution, Vectors Laboratories), FITC-LTA (1;1000 dilution, Vectors Laboratories), mouse anti-calbidin (1:1000, MilliporeSigma), and sheep anti-THP glycoprotein antibody (1;1000, Bio-Rad). Images were taken on a Nikon Eclipse TE2000-U microscope driven by MetaMorph software (Universal Imaging).

Cystic index calculation and BUN measurements. Plasma samples were collected from cardiac puncture, and kidneys were harvested in control, $P k d 1$, and $P k d 2 \mathrm{KD}$ mice at the age of 18 weeks for BUN and cyst analysis. The extent of tubular cyst formation was quantified in sagittal sections of whole kidneys. Four sections ( 2 each from the midsagittal region of each kidney) were analyzed for each experimental animal. Whole kidney images were obtained using automated image acquisition by the scan slide module in MetaMorph (Universal Imaging). Total kidney area, total cystic area, and total noncystic area were measured using the integrated morphometry feature in MetaMorph. Cystic index $=($ total cystic area/total kidney area $) \times 100$ and is expressed as a percent (31). Plasma BUN values were determined spectrophotometrically with a diacetylmonoxime-based assay kit (Stanbio Laboratory) by Yale George M. O'Brien Kidney Center.

Statistics. Data are presented as mean \pm SEM. Two-tailed Student's $t$ test was used to compare control and experimental groups. One-way ANOVA was used for comparison of several experimental groups 
with a control group, followed by a Tukey's multiple comparison. The difference between the mean values of an experimental group and a control group were considered significant if $P<0.05$.

Study approval. Experiments were carried out under protocols approved by the Yale University Institutional Animal Care and Use Committee in accordance with NIH guidelines for the ethical treatment of animals.

\section{Author contributions}

ZD performed microperfusion experiments, analyzed experimental results, and summarized data in Table 1, Table 2, Table 3, and Table 4 under the supervision of TW. XT and MM performed genotyping and induced $P k d 1, P k d 2$, and $K i f 3 a \mathrm{cKD}$ mice under the supervision of SS. TW preformed experiments with chronic treatment of $P k d 1^{-/-}$and $P k d 2^{-/-}$with DA1 antagonist. XT performed experiments of cyst analysis, IF, and imaging under the supervision of SS. AW performed mathematical model analysis. TW and AMW designed experimental approaches and draft the manuscript. All authors were involved in revising the manuscript for intellectual content. All authors read and approved the final manuscript.

\section{Acknowledgments}

We thank Lonnette Diggs and Deren Shao for expert technical assistance. Studies were supported by NIH grants R01 DK117650 (TW), RO1-DK29857 (AW), R01 DK54053 (SS), and P30DK079310 (George M. O’Brien Kidney Center at Yale).

Address correspondence to: Tong Wang, Department of Cellular and Molecular Physiology, Yale School of Medicine, 333 Cedar Street, P.O. Box 208026, New Haven, Connecticut 06520, USA. Phone: 203.785.6435; Email: tong.wang@yale.edu.

1. Schnermann J, et al. Balance between tubular flow rate and net fluid reabsorption in the proximal convolution of the rat kidney. I. Dependency of reabsorptive net fluid flux upon proximal tubular surface area at spontaneous variations of filtration rate. Pflugers Arch. 1968;304(1):90-103.

2. Gertz KH, et al. On the glomerular tubular balance in the rat kidney. Pflugers Arch Gesamte Physiol Menschen Tiere. 1965;285(4):360-372.

3. Du Z, et al. Axial flow modulates proximal tubule NHE3 and H-ATPase activities by changing microvillus bending moments. Am J Physiol Renal Physiol. 2006;290(2):F289-F296.

4. Weinbaum S, et al. Mechanotransduction in the renal tubule. Am J Physiol Renal Physiol. 2010;299(6):F1220-F1236.

5. Du Z, et al. Mechanosensory function of microvilli of the kidney proximal tubule. Proc Natl Acad Sci U S A. 2004;101(35):13068-13073.

6. Duan Y, et al. Shear stress-induced changes of membrane transporter localization and expression in mouse proximal tubule cells. Proc Natl Acad Sci U S A. 2010;107(50):21860-21865.

7. Du Z, et al. Regulation of glomerulotubular balance: II: impact of angiotensin II on flow-dependent transport. Am J Physiol Renal Physiol. 2012;303(11):F1507-F1516.

8. Du Z, et al. Regulation of glomerulotubular balance. I. Impact of dopamine on flow-dependent transport. Am J Physiol Renal Physiol. 2012;303(3):F386-F395.

9. Pazour GJ, et al. Polycystin-2 localizes to kidney cilia and the ciliary level is elevated in orpk mice with polycystic kidney disease. Curr Biol. 2002;12(11):R378-R380.

10. Torres VE, Harris PC. Progress in the understanding of polycystic kidney disease. Nat Rev Nephrol. 2019;15(2):70-72.

11. Koulen P, et al. Polycystin-2 is an intracellular calcium release channel. Nat Cell Biol. 2002;4(3):191-197.

12. Sammels E, et al. Polycystin-2 activation by inositol 1,4,5-trisphosphate-induced Ca2+ release requires its direct association with the inositol 1,4,5-trisphosphate receptor in a signaling microdomain. J Biol Chem. 2010;285(24):18794-18805.

13. Pablo JL, et al. Progress in ciliary ion channel physiology. J Gen Physiol. 2017;149(1):37-47.

14. DeCaen PG, et al. Direct recording and molecular identification of the calcium channel of primary cilia. Nature. 2013;504(7479):315-318.

15. Liu X, et al. Polycystin-2 is an essential ion channel subunit in the primary cilium of the renal collecting duct epithelium. Elife. 2018;7:e33183.

16. Woda CB, et al. Effects of luminal flow and nucleotides on $\left[\mathrm{Ca}\left(2^{+}\right)\right](\mathrm{i})$ in rabbit cortical collecting duct. Am J Physiol Renal Physiol. 2002;283(3):F437-F446.

17. Liu W, et al. Mechanoregulation of intracellular Ca2+ concentration is attenuated in collecting duct of monocilium-impaired orpk mice. Am J Physiol Renal Physiol. 2005;289(5):F978-F988.

18. Lin F, et al. Kidney-specific inactivation of the KIF3A subunit of kinesin-II inhibits renal ciliogenesis and produces polycystic kidney disease. Proc Natl Acad Sci U S A. 2003;100(9):5286-5291.

19. Traykova-Brauch $\mathrm{M}$, et al. An efficient and versatile system for acute and chronic modulation of renal tubular function in transgenic mice. Nat Med. 2008;14(9):979-984.

20. Ma M, et al. Loss of cilia suppresses cyst growth in genetic models of autosomal dominant polycystic kidney disease. Nat Genet. 2013;45(9):1004-1012. 
21. Du Z, et al. Regulation of glomerulotubular balance. III. Implication of cytosolic calcium in flow-dependent proximal tubule transport. Am J Physiol Renal Physiol. 2015;308(8):F839-F847.

22. Wu G, et al. Cardiac defects and renal failure in mice with targeted mutations in Pkd2. Nat Genet. 2000;24(1):75-78

23. Weinstein AM, et al. Flow-dependent transport in a mathematical model of rat proximal tubule. Am J Physiol Renal Physiol. 2007;292(4):F1164-F1181.

24. $\mathrm{Hu} \mathrm{MC}$, et al. Dopamine acutely stimulates $\mathrm{Na}+/ \mathrm{H}+$ exchanger (NHE3) endocytosis via clathrin-coated vesicles: dependence on protein kinase A-mediated NHE3 phosphorylation. J Biol Chem. 2001;276(29):26906-26915.

25. Baum M, Quigley R. Inhibition of proximal convoluted tubule transport by dopamine. Kidney Int. 1998;54(5):1593-1600.

26. Bourne JA. SCH 23390: the first selective dopamine D1-like receptor antagonist. CNS Drug Rev. 2001;7(4):399-414.

27. Harris PC, Torres VE. Genetic mechanisms and signaling pathways in autosomal dominant polycystic kidney disease. JClin Invest. 2014;124(6):2315-2324.

28. Weinstein AM. A mathematical model of the rat nephron: glucose transport. Am J Physiol Renal Physiol. 2015;308(10):F1098-F1118

29. Davenport JR, et al. Disruption of intraflagellar transport in adult mice leads to obesity and slow-onset cystic kidney disease. Curr Biol. 2007;17(18):1586-1594.

30. Piontek K, et al. A critical developmental switch defines the kinetics of kidney cyst formation after loss of Pkd1. Nat Med. 2007;13(12):1490-1495.

31. Shibazaki S, et al. Cyst formation and activation of the extracellular regulated kinase pathway after kidney specific inactivation of Pkd1. Hum Mol Genet. 2008;17(11):1505-1516.

32. Carrisoza-Gaytán R, et al. The mechanosensitive $\mathrm{BK} \alpha / \beta 1$ channel localizes to cilia of principal cells in rabbit cortical collecting duct (CCD). Am J Physiol Renal Physiol. 2017;312(1):F143-F156.

33. Delling M, et al. Primary cilia are not calcium-responsive mechanosensors. Nature. 2016;531(7596):656-660.

34. Wang Q, et al. Structural interaction and functional regulation of polycystin-2 by filamin. PLoS One. 2012;7(7):e40448.

35. Leyssac PP, et al. On determinants of glomerular filtration rate after inhibition of proximal tubular reabsorption. Am J Physiol. 1994;266(5 pt 2):R1544-R1550.

36. Weinstein AM. A mathematical model of the rat kidney: $\mathrm{K}^{+}$-induced natriuresis. Am J Physiol Renal Physiol. 2017;312(6):F925-F950

37. Weinstein AM. A mathematical model of the rat kidney. II. Antidiuresis. Am J Physiol Renal Physiol. 2020;318(4):F936-F955.

38. Cortell S, et al. A definition of proximal and distal tubular compliance. Practical and theoretical implications. JClin Invest. 1973;52(9):2330-2339.

39. Jensen PK, Steven K. Influence of intratubular pressure on proximal tubular compliance and capillary diameter in the rat kidney. Pflugers Arch. 1979;382(2):179-187.

40. Leyssac PP, et al. A study of proximal tubular compliances in normotensive and spontaneously hypertensive rats, and the effect of anaesthesia on the compliance. Acta Physiol Scand. 1986;126(3):341-348.

41. Aperia AC. Intrarenal dopamine: a key signal in the interactive regulation of sodium metabolism. Annu Rev Physiol. 2000;62:621-647.

42. Carey RM. Theodore Cooper Lecture: renal dopamine system: paracrine regulator of sodium homeostasis and blood pressure. Hypertension. 2001;38(3):297-302.

43. Torres VE, Harris PC. Strategies targeting cAMP signaling in the treatment of polycystic kidney disease. J Am Soc Nephrol. 2014;25(1):18-32. 